\title{
Impact of Topographic Internal Lee Wave Drag on an Eddying Global Ocean Model
}

\author{
David S. Trossman \\ Department of Earth and Environmental Sciences, University of Michigan, Ann Arbor, USA \\ Department of Atmospheric and Oceanic Sciences, McGill University, Montreal, H3A OB9 CAN \\ Brian K. Arbic \\ Department of Earth and Environmental Sciences, University of Michigan, Ann Arbor, USA \\ James G. Richman \\ Oceanography Division, Naval Research Laboratory (NRL-SSC), Stennis Space Center, \\ Mississippi, USA \\ Stephen T. Garner \\ NOAA/Geophysical Fluid Dynamics Laboratory, Princeton, New Jersey, USA \\ Steven R. Jayne \\ Physical Oceanography Department, Woods Hole Oceanographic Institution, Woods Hole, USA \\ Alan J. Wallcraft \\ Oceanography Division, Naval Research Laboratory (NRL-SSC), Stennis Space Center, \\ Mississippi, USA
}

\begin{abstract}
The impact of topographic internal lee wave drag ("wave drag" hereafter) on several aspects of the low-frequency circulation in a high-resolution global ocean model forced by winds and air-sea buoyancy fluxes is examined here. The HYbrid Coordinate Ocean Model (HYCOM) is run at two different horizontal resolutions (one nominally $1 / 12^{\circ}$ and the other $1 / 25^{\circ}$ ). Wave drag, which parameterizes both topographic blocking and the generation of lee waves arising from geostrophic
\end{abstract}

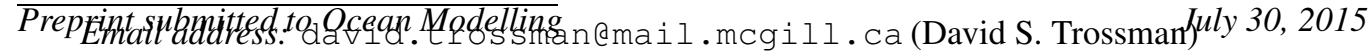


flow impinging upon rough topography, is inserted into the simulations as they run. The parameterization used here affects the momentum equations and hence the structure of eddy kinetic energy. Lee waves also have implications for diapycnal mixing in the ocean, though that is not a focus of this work.

Total near-bottom energy dissipation due to wave drag and quadratic bottom boundary layer drag is nearly doubled, and the energy dissipation due to quadratic bottom drag is reduced by about a factor of two, in simulations with an inserted wave drag compared to simulations having only quadratic bottom drag. With the insertion of wave drag, the kinetic energy is reduced in the abyss and in a threedimensional global integral. Deflection by partial topographic blocking is inferred to be one reason why the near-bottom kinetic energy can increase in locations where there is little change in dissipation by quadratic bottom drag.

Despite large changes seen in the abyss, the changes that occur near the sea surface are relatively small upon insertion of wave drag into the simulations. Both the sea surface height variance and geostrophic surface kinetic energy are reduced on global average by more than twice the seasonal variability in these diagnostics. Alterations in the intensified jet positions brought about by inserting wave drag are not distinguishable from the temporal variability of jet positions. Various statistical measures suggest that applying wave drag within a fixed distance from the seafloor is not detrimental to the model performance relative to observations. The introduction of a novel diagnostic suggests that one way to improve the wave drag parameterization is to allow the vertical deposition of lee wave momentum flux to be spatially heterogeneous. 


\section{Introduction}

In this study, we investigate the impact of topographic internal lee wave drag (hereafter, "wave drag") on low-frequency flow in a high-resolution ("eddying") global ocean general circulation model run at two different horizontal resolutions. Here, by wave drag, we mean the combined drag imparted on low-frequency flow in the water column due to partial blocking of the flow by topography (hereafter, "topographic blocking") and due to the generation of topographic internal lee waves when low-frequency flow impinges upon rough topography. We are partially motivated by the potentially important role of wave drag in mixing the abyssal ocean. The mixing associated with energy dissipation is thought to exert an important control on the large-scale circulation. Of the energy that is put into the interior geostrophic flows of the ocean (Munk and Wunsch, 1998; Webb and Suginohara, 2001), a significant fraction has been found to be taken out at the seafloor (Trossman et al., 2013).

The two primary mechanisms responsible for dissipating energy at the seafloor are believed to be the drag due to turbulence generated in the bottom boundary layer, and wave drag. Taylor (1919) demonstrated that energy is dissipated in the bottom boundary layer of the ocean (hereafter, "bottom drag"). NaveiraGarabato et al. (2004), Marshall and Naveira-Garabato (2008), and Nikurashin and Ferrari (2010a,b) suggested that energy is transferred to internal lee waves when low-frequency flow impinges upon rough topographic features. When the Froude number $(F r=V / N Z$ for near-bottom velocity $V$, near-bottom buoyancy frequency $N$, and topographic height scale $Z)^{1}$ is sufficiently small, the flow will

\footnotetext{
${ }^{1}$ Note that our definition of the Froude number is consistent with that of the atmospheric litera-
} 
move around a topographic feature rather than over it. When the Froude number is sufficiently large, the flow will move over a topographic feature and generate lee waves, which later break and cause turbulent dissipation. Global ocean models have been invaluable in investigations of the energy budget because of the difficulty in attributing dissipation to specific ocean processes using observations alone (Wright et al., 2013 and 2014, and references therein). Both bottom drag (e.g., Arbic et al., 2009) and wave drag (e.g., Trossman et al., 2013) have been shown to be important factors in the mechanical energy budgets of eddying ocean models.

Because bottom drag and wave drag both act as momentum sinks near the seafloor, they both have the potential to impact the statistics of mesoscale eddies (referred to as "eddy statistics" hereafter). Previous studies have demonstrated that the magnitude of bottom drag influences eddy statistics. Arbic and Flierl (2004), for example, showed that varying the linear bottom boundary layer drag coefficient influences the amplitude, vertical structure, and horizontal length scales of eddy kinetic energy in a two-layer, doubly periodic, quasi-geostrophic (QG) turbulence model driven by an imposed horizontally homogeneous vertically sheared mean flow. Riviere et al. (2004) and Thompson and Young (2006) performed related studies and came to similar conclusions. Arbic and Scott (2008) showed that the same qualitative behaviors are exhibited in QG turbulence models damped by a quadratic bottom drag. Hurlburt and Hogan (2008) demonstrated, using a more realistic ocean model, that changing the bottom boundary layer drag coefficient has a significant influence on the surface eddy statistics, at least when

ture, and is the reciprocal of the Froude number as defined in most of the oceanographic literature. 
a flat bottom is used. In the present paper, we will investigate the impact of wave drag on eddy statistics. To judge model sensitivity and performance relative to observations, we choose several statistics that can be computed from the output of the multiple model simulations performed here and from either satellite altimetry products or moored current meter observations. Using a realistic global eddying ocean model, Trossman et al. (2013) noted a substantial decrease in depthintegrated, area-averaged kinetic energy upon insertion of wave drag. They inferred that, as long as the vertical velocities are modified due to changes in the horizontal velocity field and these effects are not negated by changes in the sea surface height field, the insertion of wave drag alters the potential to kinetic energy conversion term. ${ }^{2}$ However, it has yet to be shown whether eddy statistics are altered upon insertion of wave drag. It is possible that the rough bottom topography of our realistic model mediates the impact of wave drag on eddy statistics because of topographic controls on the available potential energy conversion rates (Stewart et al., 2014).

Previous studies have demonstrated a need to introduce diffusivity-enhancing and/or momentum sink parameterizations, based on the dynamics of flow over

\footnotetext{
${ }^{2}$ For such high resolution models, $\mathrm{CPU}, \mathrm{I} / \mathrm{O}$, and storage limitations prevent us from saving all the diagnostics one might want to save and analyze. Because Trossman et al. (2013) was focused on the total (kinetic plus potential) mechanical energy budget, the potential to kinetic energy conversion term was not saved to model output. Because we use the same suite of model output here, once again we cannot directly compute the potential to kinetic energy conversion term and therefore do not attempt to address whether baroclinic instability has changed in the present study. Diagnosis of the potential to kinetic energy conversion term using the output we did save requires addressing discontinuities at layer interfaces, a technical issue that can be addressed in a future study.
} 
rough topography, in order to model the abyssal ocean. Decloedt and Luther (2012), for example, suggested, using their Roughness Diffusivity Model (Decloedt and Luther, 2010) and the Jayne and St. Laurent (2001) parameterization of tidal dissipation, that internal wave breaking associated with topographically generated internal lee waves and internal tides is important but is insufficient to explain diffusivities inferred from inversions of World Ocean Circulation Experiment hydrography and microstructure surveys. Melet et al. $(2013,2014)$ included parameterizations that directly impacted the diapycnal diffusivity associated with internal tide and lee wave breaking in coupled atmosphere-ice-ocean simulations. However, there is also a momentum sink associated with internal lee wave breaking. We use a momentum sink-based parameterization, as opposed to one that directly alters the diapycnal diffusivity, here. To do this, we need to utilize models with sufficiently small grid spacing to resolve eddy kinetic energy. A major goal of this study is to investigate whether the insertion of a wave drag parameterization (Garner, 2005) into an eddying ocean general circulation model alters eddy statistics and improves the comparison of modelled eddies with observations.

In atmospheric general circulation models, westerlies are significantly slowed in the presence of wave drag due to upstream blocking (Boer et al., 1984). Palmer et al. (1986) found that the slowing of the westerlies due to upstream blocking did, in fact, improve atmospheric circulation models. This improvement was more dramatic in atmospheric circulation models than any other improvement in model physics up to that time (Pierrehumbert, 1987). The impact of wave drag on the intensified jets in ocean general circulation models, however, has not been investigated. Because the abyssal flow is sensitive to wave drag (Trossman et al., 2013), we might expect to see some sensitivity of the Gulf Stream Extension path to the 
insertion of wave drag. However, Hurlburt and Hogan (2008) showed that the Gulf Stream Extension path is sensitive to whether or not the eddy-driven abyssal flow is topographically steered. Hurlburt et al. (2008) suggested that upper ocean currents are coupled to the bottom topography via flow instabilities. Keeping all of these complexities in mind, we will evaluate whether the positions of multiple intensified jets are altered upon insertion of wave drag into our model.

This manuscript is organized as follows. First, we outline the model simulations. Second, we briefly summarize our quadratic bottom boundary layer drag and topographic internal lee wave drag parameterizations. Then we describe how the presence of wave drag influences the model dynamics through comparisons of simulations with and without wave drag. We focus here on the impact of wave drag on the eddying circulation rather than the time mean flow. After that, we describe our diagnostics used to evaluate model performance with respect to observations from satellite altimetry and moored current meters. In particular, we will examine whether the insertion of wave drag improves model performance. Finally, we will suggest future directions for improving the parameterization of wave drag in ocean general circulation models.

\section{Description of model and drag formulations}

\subsection{Model Runs}

The nominally $1 / 12^{\circ}$ and $1 / 25^{\circ}$ HYbrid Coordinate Ocean Model (HYCOM; http://www.hycom.org; Bleck, 2002; Chassignet et al., 2003; Halliwell, 2004) simulations utilized here have a tripolar Mercator grid with 32 hybrid layers in the vertical direction. The layers follow isopycnal coordinates in the subsurface open ocean, z-level coordinates in weakly stratified regions of the open ocean (in- 
cluding surface mixed layers), and terrain-following coordinates in shallow areas. This hybrid choice is motivated by the strengths of these types of vertical coordinate systems in the aforementioned regions (Griffies et al., 2000). The K-Profile Parameterization (KPP; Large et al., 1994) is used to determine the vertical diffusivity and viscosity fields. KPP yields relatively strong diapycnal mixing in the mixed layer and a smooth transition to weaker diapycnal mixing below. Vertical viscosity is calculated through multiplication of the vertical diffusivity by the Prandtl number. The Prandtl number is equal to three for background mixing and one for shear instability mixing. Vertical viscosity is interpreted to take out momentum where there are both resolved and unresolved shear instabilities (Large et al., 1994). The Smagorinsky (1993) parameterization is used to determine the horizontal viscosity. It has been suggested that horizontal viscosity acts to trade wave momentum for eddy potential vorticity (Polzin, 2008, 2010). The performance of $1 / 12^{\circ}$ HYCOM without wave drag has been evaluated by Kelly et al. (2007) in the North Pacific, Srinivasan et al. (2009) in the Indian Ocean, and Chassignet et al. (2009) across the entire World Ocean. Thoppil et al. (2011) compared eddy kinetic energy in $1 / 12^{\circ}$ and $1 / 25^{\circ} \mathrm{HYCOM}$ to available velocity observations.

The global model simulations were spun-up from rest using $1.125^{\circ} \times 1.125^{\circ}$ European Centre for Medium-Range Weather Forecasts (ECMWF) Re-Analysis (ERA-40) monthly mean thermal forcing over 1978-2002 (Kallberg et al., 2004). A climatological monthly average of the forcing fields, averaged over all years, was used. During the entire spin-up period and ensuing run, the climatological wind forcing (ERA-40) is modified by adding six-hourly anomalies derived from the 2003 fields of the Navy Operational Global Atmospheric Prediction System (NOGAPS; Rosmond et al., 2002). The assumed background tidal velocity (see, 
for instance, Willebrand et al., 2001) was not constant throughout the model spinup phase. It was $5 \mathrm{~cm} \mathrm{~s}^{-1}$ for the first one and one-half years, $2 \mathrm{~cm} \mathrm{~s}^{-1}$ for the next two and one-half years, and $0 \mathrm{~cm} \mathrm{~s}^{-1}$ for the remaining years. Because we run the model for several years passed the spin-up period, the impacts of the initial tidal velocity are likely to be small.

We run HYCOM at two different horizontal resolutions in this study because we expect the higher resolution simulation to respond more dramatically than the lower resolution simulation does to wave drag. Our expectation is based on the fact that the higher resolution model has stronger barotropization and larger abyssal velocities due to enhanced vertical energy transfers (Thoppil et al., 2011). The durations of $1 / 12^{\circ}$ and $1 / 25^{\circ}$ simulations are different because of the different amounts of computational resources required to reach a reasonable spun-up state. Even if the duration of each model simulation was the same, differences could be attributed to aliasing of their eddying properties. Thus, for each resolution, we analyze an entire year of output and note, when possible, the magnitudes of seasonal signals relative to the impact of wave drag and horizontal resolution. For our analysis of the $1 / 12^{\circ}\left(1 / 25^{\circ}\right)$ HYCOM simulations without wave drag, we use outputs from the final fourteenth (thirteenth) year of the spin-up phase. We spun up the simulations with wave drag for six (four) more years starting from the end of the $1 / 12^{\circ}\left(1 / 25^{\circ}\right)$ simulations without wave drag. For our analysis of wave drag impacts, we use the outputs of the final twentieth (seventeenth) year of the $1 / 12^{\circ}\left(1 / 25^{\circ}\right)$ simulations. When wave drag is introduced, the global (depth- and area-integrated) kinetic energy divided by the global ocean area decreases from about 17, 000 to 13,000 $\mathrm{kg} \mathrm{s}^{-2}$ (see Trossman et al., 2013 - their Fig. 1, which includes a precise definition of the integral in question) in the $1 / 12^{\circ}$ simulations 
and from about 20,000 to $16,000 \mathrm{~kg} \mathrm{~s}^{-2}$ (not shown) in the $1 / 25^{\circ}$ simulations. The $1 / 12^{\circ}$ HYCOM simulations (both with and without wave drag) utilized here were first presented by Trossman et al. (2013), which the reader is referred to for further details of the simulations.

\subsection{Drag formulations}

Following previous studies (e.g., Taylor, 1919; Egbert et al., 2004; Sen et al., 2008; amongst many others), the bottom boundary stress $\left(\vec{\tau}_{B D}\right)$ is given by

$$
\vec{\tau}_{B D}=-c_{d}\left|\vec{u}_{b}\right| \vec{u}_{b}
$$

so that the energy dissipation rate $\left(E_{B D}\right)$ due to bottom boundary drag is given by

$$
E_{B D}=\rho c_{d}\left|\vec{u}_{b}\right|^{3}
$$

Here, as in Trossman et al. (2013), $c_{d}=0.0025$ is the nominal quadratic drag coefficient for HYCOM, and $\rho$ and $\vec{u}_{b}$ are respectively the density and velocity in the deepest model layer. The dissipation rate is cubic in the bottom current magnitudes, while the momentum drag is quadratic; the convention of referring to $c_{d}$ as the quadratic drag coefficient comes from the latter fact.

We briefly summarize the Garner (2005) lee wave scheme here and refer readers to Garner (2005) and Trossman et al. (2013) for more details. Garner (2005) formulated a scheme to estimate the momentum flux associated with topographic blocking and lee wave breaking resulting from low-frequency flows over rough orography. The scheme is based on a calculation of the column-integrated momentum forcing that is exact in the small-amplitude (linear) limit. An implementation of the linear analysis yields a $\operatorname{drag}, \mathbf{T} \cdot \vec{u}_{d}$, where $\vec{u}_{d}$ is the velocity averaged 
over a fixed bottom layer of thickness $H_{W D}$ and $\mathbf{T}$ is the topographic information tensor further described below. Both Arbic et al. (2010) and Trossman et al. (2013) made a choice of $H_{W D}=500$ meters based on the analysis of St. Laurent et al. (2002), which was guided by observations of internal tide dissipation in the Brazil Basin (St. Laurent et al., 2001). The bottom 500 meters approximately represents the average lee wave vertical wavelength predicted by linear theory for the scales of velocities and buoyancy frequencies that have been observed in the abyssal ocean. Averaging over a lee wave vertical wavelength is expected to return a value representative of the wave-free flow. Other work, such as that of Decloedt and Luther (2010), suggests a somewhat greater vertical extent for energy dissipation. The impact of vertically depositing wave drag over larger portions of the water column in an eddying ocean model will be the subject of future studies. In section 5 of this study, we perform a preliminary assessment of the validity of the assumption that the momentum flux is deposited only in the bottom 500 meters.

Because orography is never entirely linear, the Garner (2005) scheme adjusts the forcing for partially blocked or partially deflected flow based on scaling arguments. The scaling arguments, which employ dimensional analysis, yield a propagating drag, $D_{p}$, associated with lee wave breaking; a non-propagating drag, $D_{n p}$, associated with topographic blocking; and a linear drag limit, $D^{*} . D^{*}, D_{p}$, and $D_{n p}$ are defined in Eq. (12) of Trossman et al. (2013). The wave drag, $\vec{\tau}_{W D}$, employed in the model is given by the sum of the propagating and non-propagating components

$$
\vec{\tau}_{W D}=\left(\frac{D_{p}}{D^{*}}+\frac{D_{n p}}{D^{*}}\right)\left(\mathbf{T} \cdot \vec{u}_{d}\right) .
$$

As in Lott and Miller (1997), the magnitude of the drag associated with topographic blocking is a function of $\mathrm{Fr}$. 
To compute $\mathbf{T}, D_{p}, D_{n p}$, and $D^{*}$, we work with the abyssal hill rough topography power spectrum, $P(k, l)$, of Goff and Jordan (1988), where $\vec{k}=(k, l)$ is a horizontal wavenumber vector with zonal and meridional components, $k$ and $l$. As described in Trossman et al. (2013), we make use of the statistical roughness parameters from Goff (2010) and Goff and Arbic (2010) for $P(k, l)$, and integrate over all relevant topographic wavenumbers to calculate the topographic information tensor, $\mathbf{T}$. Here, the relevant topographic wavenumbers are given by

$$
\frac{|f|}{V}<|\vec{k}|<\frac{N}{V},
$$

where $V=\left|\vec{u}_{d}\right|$ is the near-bottom speed, $f$ is the Coriolis parameter, and $N$ is the near-bottom buoyancy frequency.

As in Trossman et al. (2013), we simplify the implementation of wave drag in our simulations by noting that the off-diagonal elements of $\mathbf{T}$ are small relative to the diagonal elements. Taking advantage of this feature, we compute a coefficient that can be used in the momentum equations (Arbic et al., 2010),

$$
r_{d r a g}=\frac{\vec{\tau}_{W D} \cdot \vec{u}_{d}}{\rho\left|\vec{u}_{d}\right|^{2}} .
$$

Here, $r_{\text {drag }}$ (units of $\mathrm{m} \mathrm{s}^{-1}$ ) is equivalent to the $c_{d}\left|\vec{u}_{b}\right|$ term for quadratic bottom drag in the momentum equations. If the thickness of the bottom layer of the model is 500 meters or larger, then $\vec{u}_{b}=\vec{u}_{d}$. Trossman et al. (2013) demonstrated, using offline model output, that this implementation of the Garner (2005) scheme yielded a similar global integral of wave drag energy flux as does the Bell (1975) theory, which is used more commonly in the oceanographic literature. 
The momentum equations that are solved in the model can be written as ${ }^{3}$

$$
\begin{array}{r}
\frac{\partial \vec{u}_{H}}{\partial t}+(\vec{u} \cdot \vec{\nabla}) \vec{u}_{H}+\frac{1}{\rho} \vec{\nabla} p+f \hat{k} \times \vec{u}_{H}+g \hat{k}=\frac{\theta\left(z>-H_{s}\right)}{\rho} \frac{\vec{\tau}_{\text {wind }}}{H_{s}} \\
-\theta\left(z<H_{B D}-z_{b}\right) \frac{c_{d}}{H_{B D}}\left|\vec{u}_{H}\right| \vec{u}_{H}-\theta\left(z<H_{W D}-z_{b}\right) \frac{\left|r_{d r a g}\right|}{H_{W D}} \vec{u}_{d} \\
-\frac{\partial}{\partial z}\left(\nu_{z} \frac{\partial}{\partial z} \vec{u}_{H}\right)-\vec{\nabla} \cdot\left(\nu_{h, 2} \vec{\nabla} \vec{u}_{H}+\nu_{h, 4} \vec{\nabla} \nabla^{2} \vec{u}_{H}\right) .
\end{array}
$$

Here, $t$ is time, $\vec{\nabla}=(\partial / \partial x, \partial / \partial y, \partial / \partial z)$ is a three-dimensional gradient operator, $\vec{u}=(u, v, w)$ is the three-dimensional velocity, $\vec{u}_{H}=(u, v)$ is the twodimensional velocity along isopycnal surfaces, $p$ is the pressure, $\hat{k}$ is a unit vector in the vertical direction, $g=9.806 \mathrm{~m} \mathrm{~s}^{-2}$ is the acceleration due to gravity, $\rho$ is the density, and $f$ is the Coriolis parameter. The right hand side of (6) displays the wind stress, bottom drag, wave drag, vertical viscosity, and horizontal viscosity terms, respectively. $\theta\left(z<H_{B D}-z_{b}\right)$ is a step function that is one in the bottom boundary drag layer of thickness $H_{B D}$ (assumed in HYCOM to be 10 meters from the bottom) and zero for all other layers. $\theta\left(z<H_{W D}-z_{b}\right)$ is a step function that is one in the layer of thickness $H_{W D}=500$ meters from the bottom, and zero for all other layers. In regions shallower than 500 meters, $H_{W D}$ is taken to be the depth of the water column. In regions deeper than 500 meters and where $H_{W D}$ is not exactly equal to the thickness of an integer number of layers, a fraction $(\xi)$ of the wave drag term is applied to the layer that contains 500 meters from the seafloor $\left(\sigma_{n}\right)$. Here, $\xi$ is equal to the fraction of $\sigma_{n}$ that is deeper than 500 meters from the seafloor. For example, if the 32nd layer is 400 meters thick and the 31st layer is 300 meters thick, then the 31 st layer experiences $\xi=(500-400) / 300=1 / 3$

\footnotetext{
${ }^{3}$ Trossman et al. (2013) wrote $\frac{\left|r_{d r a g}\right|}{H_{W D}} \vec{u}_{H}$ in their equivalent of (6), but meant to write $\frac{\left|r_{d r a g}\right|}{H_{W D}} \vec{u}_{d}$ instead. Their code correctly utilized $\vec{u}_{d}$ instead of $\vec{u}_{H}$.
} 
of the wave drag applied to the 32nd layer. The same type of procedure goes for the application of bottom drag over the bottom 10 meters. $\theta\left(z>-H_{s}\right)$ is a step function that equals one in the surface layer of thickness $H_{s}$ and zero for all other layers. $\vec{\tau}_{\text {wind }}$ is the surface wind stress, which is computed accounting for the relative velocities of the wind and surface currents (Scott and Xu, 2009). The vertical viscosity, $\nu_{z} \sim 10^{-4}-10^{-3} \mathrm{~m}^{2} \mathrm{~s}^{-1}$, is calculated inline in HYCOM using KPP (Large et al., 1994). The horizontal viscosity, which is on the order of $10^{2}-10^{3} \mathrm{~m}^{2} \mathrm{~s}^{-1}$, is also calculated inline in HYCOM with $\nu_{h, 2}$ taken to be the maximum of a Laplacian term and a Smagorinsky (1993) term and $\nu_{h, 4}$ taken to be a biharmonic term. Multiplying the momentum equations by density and velocity and performing a volume integral, we obtain a kinetic energy equation. Using this kinetic energy equation, we can investigate whether the energetics in the $1 / 25^{\circ}$ simulations behave in a similar manner to the $1 / 12^{\circ}$ simulations presented in Trossman et al. (2013). Because of the relatively small changes in the other terms at each resolution upon addition of wave drag, we only present the kinetic energy equation terms associated with bottom drag and wave drag (Table 1).

\section{Model-model comparisons}

First, we compare the model simulations with each other, considering several diagnostics. We look at the near-bottom energy dissipation rates and kinetic energies, each averaged over the final year of their respective simulations. Then the sea surface height (SSH) variance and geostrophic surface kinetic energy (SKE) are calculated from daily averaged SSH model output interpolated onto a $1 / 4^{\circ} \times 1 / 4^{o}$ grid. Model diagnostics are temporally averaged over the 
final year of the respective simulations. In order to demonstrate the global impact of wave drag, the differences between several globally averaged diagnostics with and without wave drag are listed in Table 2. Due to the large number of data points being compared $(\gg 1000)$, all of the differences tabulated are statistically significant from zero using a t-test with the degrees of freedom adjusted to account for the fact that the model configurations are not independent of each other. Thus, we do not list the confidence intervals in Table 2. Later, we will compare model results to observationally-informed estimates on the same $1 / 4^{o} \times 1 / 4^{o}$ grid from the AVISO (Archiving, Validation and Interpretation of Satellite Oceanographic; Le Traon et al., 1998; Ducet et al., 2000) project (taken from http://www.aviso.oceanobs.com/es/data/index.html).

\subsection{Subsurface kinetic energy}

Global maps of energy dissipation by bottom drag and wave drag are shown in Fig. 1, close-ups of the energy dissipation by wave drag in four regions where large field campaigns have been held are shown in Fig. 2, and global integrals of the dissipation terms are given in Table 1. The combined energy dissipation associated with bottom drag and wave drag in the simulations with wave drag is nearly twice as large as the bottom drag dissipation in the simulations without wave drag. The dissipation by bottom drag alone is reduced in the simulations with wave drag versus those without wave drag. We find a small increase in both bottom drag and wave drag dissipation at higher resolution (Fig. 1; Table 1). This is consistent with the enhancement of bottom flow as horizontal resolution increases, also seen in other studies (e.g., Thoppil et al., 2011). In order to better show some of the fine details in our simulations, we show close-ups of the wave drag dissipation in four regions in Fig. 2. The FLEAT (FLow Encountering Abrupt Topography; 
Fig. 2a), DIMES (Diapycnal and Isopycnal Mixing Experiment in the Southern Ocean; Fig. 2b), KESS (Kuroshio Extension Study System; Fig. 2c), and SOFine (Southern Ocean Finestructure; Fig. 2d) observational campaign regions reveal orders of magnitude variation in the energy dissipation by wave drag over short ( $\sim 10 \mathrm{~km}$ ) distances, particularly in regions with abrupt changes in topography (e.g., the FLEAT region).

The $1 / 25^{\circ}$ simulations have greater near-bottom kinetic energy than the $1 / 12^{\circ}$ simulations, but introduction of wave drag into the $1 / 25^{\circ}$ simulation reduces the near-bottom kinetic energy to nearly the same level as the $1 / 12^{\circ}$ simulation with wave drag. Here, Fig. 3, which displays the kinetic energy averaged over the bottom 500 meters in the simulations, demonstrates that near-bottom kinetic energy is enhanced with horizontal resolution, although the effect is much less dramatic in the simulations with wave drag than in those without wave drag. The near-bottom kinetic energies are reduced by about $60 \%$ with the inclusion of wave drag in the $1 / 25^{\circ}$ simulations (Figs. 3b,d; Table 2 ) and by about $20 \%$ in the $1 / 12^{\circ}$ simulations (Figs. 3a,c; Table 2). Consequently, the near-bottom kinetic energies in the $1 / 25^{\circ}$ simulation with wave drag are only slightly larger than those in the $1 / 12^{\circ}$ simulation with wave drag (Figs. 3c-d; Table 2). The near-bottom stratification also decreases upon insertion of wave drag (Trossman et al., 2013 - see their Figs. 11a-b for the $1 / 12^{\circ}$ simulations; not shown for the $1 / 25^{\circ}$ simulations). A smaller near-bottom stratification in the $1 / 25^{\circ}$ simulation than in the $1 / 12^{\circ}$ simulation when wave drag is included implies a larger Froude number of the near-bottom flow in the higher resolution simulation, which would lead to less dissipation by wave drag in the higher resolution simulation if nothing else changes. The nearbottom kinetic energy is also reduced with the introduction of wave drag at both 
$1 / 12^{\circ}$ and $1 / 25^{\circ}$ resolutions and is only slightly larger in the $1 / 25^{\circ}$ simulation than in the $1 / 12^{\circ}$ simulation when wave drag is included. However, the slight increase in kinetic energy in the higher resolution wave drag simulation is decisive for the dissipation. Because the near-bottom kinetic energy is the dominant factor in the energy dissipation associated with wave drag (Trossman et al., 2013), changes in the near-bottom kinetic energy explain the small increase in the wave drag dissipation between the two resolutions (Figs. 1e-f).

Differences in bottom drag dissipation upon insertion of wave drag cannot be entirely explained by a simple reduction in near-bottom kinetic energy associated with wave drag. Differences in bottom drag dissipation without minus with wave drag (Fig. 4a) are compared with differences in a power of the near-bottom kinetic energy (KE ${ }^{3 / 2}$ so that units are consistent with $\left|\vec{u}_{d}\right|^{3}$ in Eq. 2) without minus with wave drag (Fig. 4c) here. (We only show difference plots for the $1 / 12^{\circ}$ simulations because the $1 / 25^{\circ}$ simulations behave similarly. Results shown in Fig. $4 \mathrm{c}$ are qualitatively similar if we use $\mathrm{KE}$ instead of $\mathrm{KE}^{3 / 2}$.) The correlation between these differences is 0.66 where $\mathrm{KE}^{3 / 2}$ is larger without wave drag and -0.21 where $\mathrm{KE}^{3 / 2}$ is larger with wave drag. If the changes in bottom drag dissipation and kinetic energy were entirely due to the additional term we added to the momentum equations, then both the bottom drag dissipation and $\mathrm{KE}^{3 / 2}$ would decrease everywhere. However, there are a few locations where bottom drag dissipation is larger when wave drag is included (Fig. 4b and blue in Fig. 4a) and many locations where $\mathrm{KE}^{3 / 2}$ is larger with wave drag (Fig. $4 \mathrm{~d}$ and blue in Fig. 4c). Furthermore, when wave drag is included, the bottom drag dissipation can be unchanged in the regions where $\mathrm{KE}^{3 / 2}$ increases. This suggests that, as a result of adding wave drag, the near-bottom kinetic energy changes cannot ex- 
plain all of the alterations in bottom drag dissipation. The dynamical adjustments such as those that result from partial blocking of waters that can no longer flow over a topographic feature after wave drag is applied must explain some of the changes. The locations where $\mathrm{KE}^{3 / 2}$ increases upon insertion of wave drag flank topographic ridges (Fig. 4c). The increase in $\mathrm{KE}^{3 / 2}$ in these regions is likely associated with topographic deflection (see, e.g., Rintoul et al., 2014), which arises due to the presence of topographic blocking built into the Garner (2005) scheme.

\subsection{SSH variances and geostrophic SKEs}

The SSH variance is computed from daily averages of the model SSH field, $\eta$. The geostrophic SKE is computed as

$$
S K E=0.5\left(\overline{u_{g}^{2}+v_{g}^{2}}\right)
$$

where $u_{g}=-(g / f)(\partial \eta / \partial y)$ and $v_{g}=(g / f)(\partial \eta / \partial x)$ are the geostrophic zonal and meridional velocities respectively, and “" denotes a temporal mean. The geostrophic velocities are computed using the nine-point stencil method of Arbic et al. (2012). Because the geostrophic velocities become poorly defined near the equator, we mask out the geostrophic SKEs from $5^{\circ} \mathrm{S}$ to $5^{\circ} \mathrm{N}$.

The modelled SSH variances and their differences computed on the $1 / 4^{\circ} \times$ $1 / 4^{\circ}$ AVISO grid are shown in Figs. 5a-b and 6. For the sake of comparison, the AVISO SSH variance, averaged over 1992-2008, is shown in Fig. 5c. The modelled SSH variances are largest in the western boundary currents and the Antarctic Circumpolar Current (ACC; Figs. 5a-b), as in many previous studies (e.g., Maltrud and McClean, 2005 - their Figs. 12a-b). SSH variance differences between the simulations with versus without wave drag, at $1 / 12^{\circ}$ and $1 / 25^{\circ}$ resolutions, are 
shown in Figs. 6a and 6b, respectively. Differences between the simulations without wave drag at the two different resolutions are shown in Fig. $6 \mathrm{c}$ and differences between the simulations with wave drag at the two different resolutions are shown in Fig. 6d. There is a non-zero effect of both adding wave drag and increasing horizontal resolution on the SSH variance (Table 2). The globally averaged SSH variance is about $10 \%$ smaller during July through December in each of the simulations without wave drag than during January through June. There is about a $20 \%$ difference (approximately double that of the seasonal signal) in the globally averaged SSH variance when wave drag is added (Table 2), suggesting that the effect of adding wave drag is larger than the model's seasonal variability. When wave drag is inserted, the changes are on the order of $100 \%$ of the initial values of the SSH variance in the subtropical Indian Ocean, the ACC, western boundary currents, and rings to the west of the Agulhas Current. At a given grid point where the SSH variance is reduced (increased) upon insertion of wave drag (Figs. 6a-b), the SSH variance is generally increased (reduced) upon going to higher resolution (Fig. 6c-d). However, these local effects cannot be interpreted as being induced by wave drag without considering eddy-induced effects (see below).

The modelled geostrophic SKEs and their differences computed on the $1 / 4^{\circ} \times$ 1/4 $4^{\circ}$ grid are shown in Figs. 7a-b and 8, which are organized as in Figs. 5a-b and 6. For the sake of comparison, the geostrophic SKE computed from AVISO, averaged over 1992-2008, is shown in Fig. 7c. The modelled geostrophic SKEs are largest in the western boundary currents and the ACC (Figs. 7a-b), as in previous studies (e.g., similar to the surface kinetic energy shown in Hallberg and Gnanadesikan, 2006 - their Fig. 6). Figures 8a-b demonstrate that the geostrophic SKE increases at many grid points and decreases at many other locations upon 
addition of wave drag. A global average shows a decrease in geostrophic SKE when wave drag is included (Table 2). The globally averaged geostrophic SKE is about 7.6\% smaller during July through December in each of the simulations without wave drag than during January through June. There is about a 15\% difference (approximately double that of the seasonal signal) in the globally averaged geostrophic SKE when wave drag is added (Table 2), suggesting once again that the effect of adding wave drag is larger than the model's seasonal variability. The geostrophic SKE increases in most locations with higher resolution (Figs. 8c-d). The regions showing the largest changes in the geostrophic SKE with the addition of wave drag and higher resolution in Fig. 8 are generally correlated with the regions showing greatest impact in the SSH variance maps of Fig. 6. As with the SSH variance, at a given grid point where the geostrophic SKE is reduced (increased) upon insertion of wave drag, the geostrophic SKE is generally increased (reduced) upon going to higher resolution (Figs. 8a-b and Figs. 8c-d), but the effect of both adding wave drag (Table 2) and going to higher resolution (not listed) on the geostrophic SKE is non-zero. The response of the geostrophic SKE to the presence of wave drag is slightly greater at $1 / 25^{\circ}$ resolution (Fig. 8b; Table 2) than at $1 / 12^{\circ}$ resolution (Fig. 8 a; Table 2 ).

Because eddies can confound the interpretation of regional changes due to insertion of wave drag, we investigate whether we can find consistent changes in both the $1 / 12^{\circ}$ and $1 / 25^{\circ}$ simulations that are not associated with increases in resolution. In Fig. 9, we plot the sign of the changes in the SSH variance (Figs. 9a-b) and geostrophic SKE (Figs. 9c-d) upon insertion of wave drag when they are consistent, regardless of whether the horizontal resolution is $1 / 12^{\circ}$ or $1 / 25^{\circ}$. This accounts for some eddy-induced effects. The SSH variance decreases in broad 
regions that include intensified jets such as the Gulf Stream Extension (Figs. 9a,c) and Kuroshio Extension (Figs. 9b,d) and increases in several surrounding areas. The geostrophic SKE decreases in narrowly striped regions within intensified jets and increases at sparsely distributed locations surrounding the intensified jets. Because we see broad features instead of randomly distributed pixels in Fig. 9, especially in the upper subplots, we infer that wave drag is responsible for these features rather than individual eddy effects. Further evidence that wave drag is responsible for the changes shown in Fig. 9 is that, when we apply an extra conditional statement that the sign of the changes in the diagnostic field cannot be the same when going from $1 / 12^{\circ}$ to $1 / 25^{\circ}$ resolution whether wave drag is included or not, the broad features seen in Fig. 9 are virtually unchanged (not shown).

\section{Model-observation comparisons}

To assess whether inclusion of wave drag improves the simulations, we use two observational datasets. One dataset is the Global Multi-Archive Current Meter Database (e.g., Scott et al., 2010) which contains frequently sampled velocity data at specific locations (Fig. 10) in the World Ocean (taken from http://stockage.univbrest.fr/ scott/GMACMD/updates.html). These observations were quality controlled for effects such as blow-over and used in Timko et al. (2013). The current meter observations offer sparse spatial coverage and provide little information about the surface dynamics. For global coverage of surface fields, we use the global $1 / 4^{o} \times 1 / 4^{o} \mathrm{SSH}$ product from AVISO. To calculate the geostrophic SKE from observations, the mean sea surface product of Andersen and Knudsen (2009) and Andersen (2010) is used to supplement the AVISO SSH anomalies. We added the mean sea surface product to the sea surface height anomalies from AVISO. 
Because of the temporal and spatial smoothing inherent in the optimal interpolation routines used to create the AVISO data, it should be noted that the magnitude of the AVISO-derived geostrophic SKE, (7), is somewhat deficient.

The diagnostics used here to compare the model simulations with observations are as follows. Vertical profiles of the kinetic energies from each model simulation are compared with those from the current meter observations at the locations shown in Fig. 10. Maps of the SSH variances and geostrophic SKEs inferred from the AVISO product are compared with maps computed from the $1 / 25^{\circ}$ model simulations. Several intensified jet positions and their variability are also shown. Three quantiles (including the 50\% quantile, or median) are shown in boxplots for three diagnostics: the kinetic energy at each of the current meter locations, SSH variance on the $1 / 4^{\circ} \times 1 / 4^{\circ}$ AVISO grid, and geostrophic SKE on the $1 / 4^{o} \times 1 / 4^{\circ}$ AVISO grid. In addition, three statistics (i.e., correlation, standard deviation, and root-mean-square deviation) are computed and summarized by Taylor diagrams (Taylor, 2001) for three diagnostics: the depth binned profiles of kinetic energy averaged over all of the current meter locations, zonally averaged SSH variance, and zonally averaged geostrophic SKE.

\subsection{Subsurface kinetic energy}

Vertical profiles of kinetic energy are computed by geometrically averaging 4 the kinetic energy, $0.5\left(\overline{u^{2}+v^{2}}\right)$, over all of the current meter locations (Fig. 10) from our database. The current meter velocities (with zonal and meridional components, $u$ and $v$, respectively) are low-pass filtered to provide a closer frequency

\footnotetext{
${ }^{4}$ Geometric averages are more appropriate than arithmetic averages for kinetic energy, which has a log-normal-like distribution.
} 
match to the daily averaged model output. All current meter time series used here are at least one-half year in duration. In order to compare the model output with observations at binned depth levels, we first vertically interpolate the daily averages of the model velocities to the depth levels of the current meter observations. We then bin the daily averages of the model velocities to a depth level grid, compute the kinetic energy, and perform the temporal and geometric spatial averaging. The temporal averaging is performed over the final year of each model simulation, the nearest horizontal grid points to the current meter locations shown in Fig. 10 are utilized, and the spatial averaging is performed over each of these horizontal locations to arrive at an average vertical profile. The binned depth levels were chosen to be 500 meters apart because this is a typical resolution of the moorings that have multiple current meters and because this is a typical layer thickness in the abyss in the model simulations. Because there are so few (on the order of ten) current meter observations at about 4500 meters depth and below, we only consider the average vertical profile of kinetic energy at 4000 meters depth and above. The average of the kinetic energy computed as a function of depth from the current meter database (thick solid black curve) at the locations shown in Fig. 10 and at the nearest grid point and final year of the model simulations (all other colors) is shown in Figs. 11a-d. The ratios of the filtered observations to the modelled kinetic energy at a function of binned depth level is shown in Fig. 11e and the number of observations within each binned depth level is shown in Fig. 11f.

The vertical structure of the modelled kinetic energy at the current meter locations is altered by the presence of wave drag. The model simulations that include wave drag see a reduction in the kinetic energy near the seafloor (Fig. 3) and when globally averaged over all horizontal locations and depths (Trossman et al., 2013 
- see their Fig. 1). The simulated kinetic energies are in better agreement with filtered observations at shallower depths when wave drag is included in the simulations (Fig. 11e). As seen most clearly in Fig. 11e, the kinetic energy averaged over the current meter locations shown in Fig. 10 is enhanced upon addition of wave drag to the model above about 3000 meters and reduced below about 3000 meters for both model resolutions. In all of our simulations, the vertical gradient in modelled kinetic energy approaching the surface is much too steep relative to the observations (albeit, within one geometric standard deviation of the vertical gradient in the observations). Our application of wave drag in the bottom 500 meters does not correct this problem. The simulated kinetic energy profiles are only within one geometric standard deviation of the filtered observations of kinetic energy profiles above about 3500 meters depth. The filtered observations of kinetic energy profiles are only within one geometric standard deviation of the simulated kinetic energy profiles above about 1500 meters depth in the $1 / 12^{\circ}$ simulations and above about 2750 meters depth in the $1 / 25^{\circ}$ simulations. A twosample Kolmogorov-Smirnov test (Shorack and Wellner, 1986) rejects the null hypothesis that the kinetic energies at each sampled location of the simulations and those of the low-pass filtered observations are from the same distribution to a 95\% confidence level at all depths between about 750 and 4000 meters. However, the two-sample Kolmogorov-Smirnov test cannot reject this null hypothesis for most depths above 750 meters in the $1 / 12^{\circ}$ simulation with wave drag, and for depths above 1000 meters and below 3000 meters in the $1 / 25^{\circ}$ simulation with wave drag (not shown).

The kinetic energy from the filtered observations tends to be larger than that of the model simulations, but the kinetic energies are closer to those from filtered 
observations at higher resolutions (Figs. 11a-e). At lower resolutions, the bottom kinetic energy is quite weak (Figs. 3 and 11a-d). This is likely, at least in part, due to the fact that dissipation by horizontal viscosity is larger at lower resolutions (calculated but not listed in Table 1; Wallcraft et al., 2005), implying that dissipation at the seafloor, and hence bottom kinetic energy, must be lower. Also, at lower resolutions, the surface velocities are weaker than in the observations (Thoppil et $a l ., 2011)$. Therefore, part of the discrepancy between the observations and model output in the average vertical profiles of kinetic energy will remain until sufficiently high horizontal resolutions are reached. Part of the discrepancy between the observations and model output in the deep ocean is likely attributable to the poor sampling of current meter observations (Fig. 11f). Sparse sampling accounts for the qualitative differences seen in the bottom 500 or so meters of Figs. 11a-d and globally averaged kinetic energy in the bottom 500 meters (Table 2). Sparse sampling is also likely to account for the qualitative differences seen in the kinetic energy closer to the surface upon addition of wave drag in Figs. 11a-d and globally averaged geostrophic SKE (Table 2). We note that current meter locations may be chosen based on the features of the region of interest (e.g., near a topographically enhanced current or in an intensified jet). Small differences between the topography or intensified jet positions in the model versus the ocean are hypothesized to partially explain the orders of magnitude differences between the model and observations at individual grid points, but this is beyond the scope of the present study.

\subsection{SSH variances and geostrophic SKES}

Differences between the $\mathrm{SSH}$ variance of the $1 / 25^{\circ}$ model simulations, averaged over their final years, and the SSH variance of the AVISO product, averaged 
over the 1992-2008 period, are shown in Figs. 12a-b. Recall that the global map of the 1992-2008 AVISO product average of the SSH variance is shown for reference in Fig. 5c. This diagnostic reveals the most obvious improvement in the model simulations relative to observations with the insertion of wave drag. Not only is the difference map improved in the Kuroshio Extension region with the inclusion of wave drag (black circles in Figs. 12a-b), but in most locations, the SSH variances from the $1 / 12^{\circ}$ (not shown in Fig. 12) and $1 / 25^{\circ}$ model simulations are closer to the AVISO SSH variances when wave drag is inserted. The percent of the ocean area where modelled SSH variance is in better agreement with AVISO upon insertion of wave drag is $61.6 \%(61.5 \%)$ in the $1 / 12^{\circ}\left(1 / 25^{\circ}\right)$ simulations.

Generally, the modelled SSH variances are well correlated with those from AVISO (compare Figs. 5a-b with Fig. 5c). However, at locations where the AVISO SSH variance is relatively small, the modelled SSH variances can be orders of magnitude larger or smaller than those from AVISO (not shown). The SSH variance magnitudes are too large in a number of regions (e.g., the Subtropical Indian Ocean, the Subantarctic Front of the ACC, the tails to the southwest and northeast of some of the other intensified jets, and the Bering Sea) in the simulations without wave drag (Fig. 12a), and the magnitudes are reduced upon insertion of wave drag (Figs. 6a-b). Some of these discrepancies (e.g., the Bering Sea) may be due to the relatively poor sampling in ice-covered regions in the AVISO product. There are some features in the model simulations in non-polar regions that are absent in the AVISO product. Regions such as the Subtropical Indian Ocean and the rings in the wake of the Agulhas Current contain large SSH variances in the model simulations and little SSH variance in AVISO. The zonal averages of the SSH variance are largest in the Southern Ocean and in latitudes where there 
are western boundary currents, as shown in Fig. 13a. The zonal averages of the SSH variance from the simulations with wave drag are clustered together. The averaged SSH variances from the simulations without wave drag are also clustered together. Only at the equator, where the SSH variance is underestimated by all of the models, are all four of the simulations clustered together.

Differences between the geostrophic SKE computed via (7) using the $1 / 25^{\circ}$ model simulations, averaged over their final simulation year, and the AVISO product, averaged over 1992-2008, are shown in Figs. 12c-d. Recall that the global map of the 1992-2008 AVISO product average of the geostrophic SKE is shown for reference in Fig. 7c. As with the SSH variance, the geostrophic SKE reveals some improvement in the model simulations relative to AVISO when wave drag is inserted. The improvement in the geostrophic SKE is again most apparent in the Kuroshio Extension region (black circles in Figs. 12c-d). The percent of the ocean area where the modelled geostrophic SKE is in better agreement with AVISO upon insertion of wave drag is $55.1 \%(54.5 \%)$ in the $1 / 12^{\circ}\left(1 / 25^{\circ}\right)$ simulations. Regardless of whether a six or twelve month average is used, the percent of the ocean area where improvements are seen in comparison to AVISO upon insertion of wave drag is greater 50\% for both the SSH variance and geostrophic SKE. Although the differences due to wave drag are small (improvements at not much more than $50 \%$ of grid points), because of the large number of grid points involved, they are statistically significant.

The zonal average of the geostrophic SKE, shown in Fig. 13b, is less sensitive to the inclusion of wave drag than is the zonal average of the SSH variance (Fig. 13a). While the geostrophic SKE is sometimes increased and sometimes decreased upon addition of wave drag (Figs. 8a-b), the zonal average of the 
geostrophic SKE is generally reduced upon addition of wave drag (Fig. 13b). It is a known problem that the AVISO geostrophic SKE are energy deficient (e.g., Chelton et al., 2011). However, the simulations are known to be energy deficient as well based on previous comparisons with in situ current meter and drifter observations (Fig. 11; Thoppil et al., 2011).

Consistent with previous literature, it is unclear whether an improvement in the Gulf Stream separation is achieved. The ability to either resolve the first baroclinic Rossby radius of deformation (Bryan et al., 2007) or exceed the critical Richardson number (Dengg, 1993) has been found to be amongst the most important factors when complicated topography is utilized (Hurlburt and Hogan, 2008) for decent representation of Gulf Stream separation. Both of our model resolutions exceed the necessary thresholds. However, these conditions are not sufficient because parameterization of horizontal viscosity is also important (Bryan et al., 2007) and the horizontal viscosity does not change with one consistent sign in our simulations in this region upon inclusion of wave drag (Trossman et al., 2013 - see their Fig. 8c). Because differences in horizontal viscosity have also been found to affect the positions of the jets (Bryan et al., 2007), it is important to examine whether the intensified jet positions have changed upon addition of wave drag to the simulations.

\subsection{Intensified jet positions and their variability}

Motivated by the significant impact of wave drag on SSH variance (Fig. 6), we investigate whether wave drag alters the positions of several intensified jets. While jet positions in atmospheric models are improved upon addition of wave drag (Palmer et al., 1986), we expect that the intensified ocean jet positions will not be drastically altered (see earlier discussion). Following Kelly et al. (2007), we 
define jet positions by assuming a Gaussian distribution in the core of intensified jets so that the SSH field, $\eta$, is given by

$$
\eta(y)=A \operatorname{erf}\left(\frac{y-y_{c}}{\theta_{c}}\right),
$$

where $y$ is the latitude, $y_{c}$ is the latitudinal position of the core of the intensified jet, $\theta_{c}$ is half of a degree latitude, $A$ is the amplitude of the $\operatorname{SSH}$, and $\operatorname{erf}(z)=$ $(2 / \sqrt{\pi}) \int_{0}^{z} d y^{\prime}\left[\exp \left(-y^{\prime 2}\right)\right]$. Using Monte Carlo simulations of $A$ and $y_{c}$, we find $A$ and $y_{c}$ for the Gulf Stream Extension, Kuroshio Extension, Subantarctic Front of the ACC, Brazil - Malvinas Confluence Current, and Agulhas Return Current or Retroflection regions. We evaluate $y_{c}$ at each longitude where these intensified jets are defined according to this method (Fig. 14) and note the changes in $A$ upon addition of wave drag at the same locations. The position of the Kuroshio Extension jet in each of the simulations presented here (Fig. 14b) is similar to that of Kelly et al. (2007) - see their Fig. 3b. In some locations (e.g., the Indian Ocean), the method of Kelly et al. (2007) breaks down due to the loss of intensification of the jet, branching off into other currents, or other factors (not shown).

The average intensified jet positions (solid curves) over 1992-2008 from AVISO and over an entire final year of each model simulation are shown in Fig. 14. In contrast to the behavior in atmospheric models (e.g., Eckermann, 2011; and references therein), inserting wave drag into an ocean model changes neither the position (Fig. 14) nor the variability (not shown) of the intensified jets substantially. The changes in jet positions with wave drag or increased horizontal resolution all lie within one temporal standard deviation of the results from the other simulations (not shown). There is also no visually apparent change in the coefficient, $A$, in (8) when wave drag is added, but there is a small change when the resolution is increased (not shown). The finding of Hurlburt and Hogan (2008) that strong 
abyssal flows are needed for topographic steering that in turn influences the upper flows is not contradicted here. The addition of wave drag weakens the abyssal flows, thus reducing the impact on the intensified jets.

\subsection{Boxplots and Taylor diagrams}

To be more quantitative about model performance relative to the AVISO and current meter products, three $(25 \%, 50 \%$, and $75 \%)$ quantiles and three other summary statistics (root-mean-square deviation, standard deviation, and correlation) are presented below. These statistics are summarized in boxplots (Figs. 15a,c,e), which show the distribution of each diagnostic considered here, and in Taylor diagrams (Taylor, 2001; Figs. 15b,d,f), which show how well the model simulations match the observationally informed products. The geometric spatial standard deviations over the temporal average of the current meter and AVISO data $\left(\sigma_{o b s}\right)$ and over a temporal average of each model's output $\left(\sigma_{\text {model }}\right)$ are related to the root-mean-square deviation (RMSD) over space and the spatial correlation $\left(\rho_{c o r r}\right)$ by

$$
\mathrm{RMSD}^{2}=\sigma_{\text {model }}^{2}+\sigma_{\text {obs }}^{2}-2 \sigma_{\text {model }} \sigma_{\text {obs }} \rho_{\text {corr }} .
$$

These three Taylor diagram statistics are computed between the model-based and observationally-informed diagnostics. Following the presentation method of Taylor (2001), these statistics are shown in Figs. 15b,d,f. The model simulation with its symbol closest to the bullseye (black dot) of the RMSD (green contours in each panel of Figs. 15b,d,f) on the abscissa (correlation of one and zero standard deviation difference with the observationally-informed diagnostic estimates) can be interpreted to have the best performance. However, the correlation statistic is more robust than the others at measuring model improvement. The spatial pattern 
of the errors associated with a data product are not expected to coincidentally account for higher correlation when a model is altered, but it is possible for RMSD to decrease upon altering a model due to either deficiencies in the data product (e.g., those described by Chelton et al., 2011, for AVISO) or a lack of model resolution (e.g., Thoppil et al., 2011).

The boxplots are included to provide information that the Taylor diagrams do not provide, including the distribution and outlier behavior of each of the model diagnostics. The black boxes in the boxplots indicate the $25 \%$ to $75 \%$ quantiles, while the median (50\% quantile) is inside each box (red lines). The black "whiskers" on the boxplots indicate the the minimum and maximum values in the data after excluding outliers (red plusses), determined with Matlab's boxplot subroutine. Outliers are defined by a threshold criterion. Let $\mathrm{Q}_{1}$ be the lower bound of the box in the boxplot, $\mathrm{Q}_{3}$ be the upper bound of the box in the boxplot, and $\mathrm{IQR}=\mathrm{Q}_{3}-\mathrm{Q}_{1}$ be the interquartile range. Then if a data point is below $\mathrm{Q}_{1}-1.5 \times \mathrm{IQR}$ or above $\mathrm{Q}_{3}+1.5 \times \mathrm{IQR}$, that data point is viewed as being too far from the central values to be reasonable, which makes it an outlier. Boxplots for each of the model simulations and observationally informed products are shown for the SSH variance, geostrophic SKE, and kinetic energy at current meter locations in Figs. 15a,c,e.

Because our model diagnostics are not normally distributed, our statistics in the Taylor diagrams may be skewed if we evaluate them using each data point without transforming the data to be more normally distributed. Therefore, after temporally averaging over the final year of each model simulation and the entire length of the time series of the AVISO and current meter products, quantiles are computed for the base 10 logarithms of the SSH variance and geostrophic SKE 
on the AVISO $\left(1 / 4^{\circ} \times 1 / 4^{\circ}\right)$ grid and the kinetic energy at the current meter locations. However, because the logarithms of the SSH variance and geostrophic SKE diagnostics are still not quite normally distributed across the World Ocean (not shown), we use a logarithm of the zonal average of the SSH variance and geostrophic SKE from $66^{\circ} \mathrm{S}$ to $66^{\circ} \mathrm{N}$ (the latitudes with AVISO coverage). Logarithms of the zonal averages and geometrically averaged vertical profile produce more normally distributed diagnostics. For the kinetic energy at the current meter locations, on the other hand, we use a logarithm of the geometrically averaged profile between 4000 meters depth and the surface in 500 meter depth bins. Due to the dearth of observations in the abyss, comparing the modelled kinetic energy with current meter data below about 4000 meters depth is questionable. Our conclusions are not qualitatively different if we include deeper depths. The boxplots in Figs. 15a,c,e show that, after transforming the data via applying logarithms and spatially averaging, the data are more normally distributed for each diagnostic.

All three diagnostics suggest that the model is not made worse in a global average with the addition of wave drag. Because the quantiles for both the SSH variance and geostrophic SKE change very little when wave drag is included in the simulations (Figs. 15a,c), we look at the Taylor diagrams for these diagnostics. The simulations with wave drag are clustered together and the simulations without wave drag are clustered together in the SSH variance diagnostic (Fig. 15b), suggesting that wave drag does more to improve the model than adding resolution. Wave drag unambiguously improves both the $1 / 12^{\circ}$ and $1 / 25^{\circ}$ HYCOM simulations in the SSH variance (Figs. 15b) in all three statistics. The locations where this improvement occurs can be seen in Figs. 12a-b. Addition of wave drag improves the performance of the geostrophic SKE from the $1 / 25^{\circ}$ simula- 
tion in all three statistics, but makes little difference at $1 / 12^{\circ}$ (Fig. 15d). Because the AVISO maps are deficient in kinetic energy, the conclusion that the model is improved in the geostrophic SKE may be fortuitous. A lower resolution simulation may appear to agree more closely with the geostrophic SKE from AVISO. Therefore, improvement in the RMSD statistic should be discounted. Some improvement can be seen in particular locations but not in others in Figs. 12c-d. At both resolutions, the quantiles of the kinetic energy in each simulation are closer to those of the current meter observations when wave drag is included (Fig. 15e). There is a general increase in the quantiles upon insertion of wave drag because most of the observations are near the surface, where the kinetic energy increases. Because the closer agreement with observations using this metric may be due to undersampling the abyssal ocean, we look at the Taylor diagram of the average vertical profile, thus downweighting sampling issues. Wave drag improves the average kinetic energy profile at both horizontal resolutions (Fig. 15f) in its RMSD and correlation. The depths where this improvement occurs can be seen in Fig. $11 \mathrm{e}$.

\section{Vertical deposition of lee wave momentum flux}

Because the internal lee wave momentum flux is likely to be more accurately modelled by allowing the drag to be distributed over varying portions of the water column, we investigate the validity of the assumption used in the present manuscript that wave drag is locally applied in the bottom 500 meters. We do this by calculating an "effective velocity," $V_{\text {eff }}=$ (total dissipation rate)/(horizontal momentum stress). The importance of considering a vertical varying velocity field can be quantified by using the wave drag coefficient, $r_{d r a g}$, and the velocity 
in the bottom 500 meters, $\left|\vec{u}_{d}\right|=V$. We define the effective velocity by

$$
V_{e f f}=\frac{\int d z \vec{u} \cdot \frac{d \vec{\tau}_{W D}}{d z}}{\int d z \frac{d\left|\vec{\tau}_{W D}\right|}{d z}} .
$$

Because $\vec{u}_{d} \cdot d \vec{\tau}_{W D} / d z=d\left(\rho r_{d r a g} V^{2}\right) / d z$ and $d\left|\vec{\tau}_{W D}\right| / d z \approx d\left(\rho r_{d r a g} V\right) / d z$, the ratio, $V_{e f f} / V$, is computed with

$$
\frac{V_{e f f}}{V} \approx \frac{\overline{r_{d r a g} V^{2}}}{\overline{r_{d r a g}} \bar{V}^{2}},
$$

where the "-" indicates a temporal average over the final year of the model simulation. The energy dissipation rate should be approximately equal to the product of the near-bottom velocity and the horizontal momentum stress. Thus, if $\rho r_{d r a g} \int d x \int d y\left|\vec{u}_{d}\right|^{2} \neq \rho r_{d r a g} \int d x \int d y \int_{z_{b}}^{z_{b}-H_{W D}} d z|\vec{u}(z)|^{2}$, then $V_{\text {eff }} / V \neq 1$. $V_{\text {eff }}<V$ suggests that there is too much wave drag because either non-local effects are important or the drag is preferentially occurring in layers where the Froude number is smaller. Thus, we show the ratio of $V_{e f f} / V$ in Fig. 16. Because the results are qualitatively similar in the $1 / 25^{\circ}$ model simulation with wave drag, we only show $V_{\text {eff }} / V$ from the $1 / 12^{\circ}$ HYCOM simulation with wave drag.

The red regions in Fig. 16 have approximately correct energy dissipation rates due to wave drag. These regions have relatively strong stratification (Trossman et al., 2013 - see their Figs. 11a-b) and are in either coastal areas or locations that underly intensified jets with relatively large energy dissipation rates associated with wave drag (Figs. 1e-f). The abyssal plains (e.g., along the equator and in the North Pacific Ocean), on the other hand, have relatively small stratification and energy dissipation rates. The wave drag we applied in the abyssal plains regions may be too large (blue in Fig. 16) and distributing the momentum flux over a bottom boundary layer thickness (spanning multiple vertical model layers) 
larger than 500 meters is recommended for future simulations. Because we do not know a priori how the non-uniform spatial pattern in Fig. 16 will impact the dynamics, and because $V_{e f f} / V$ is less than unity over most of the global ocean area, it is left for a future study to investigate how the application of wave drag distributed throughout the entire water column alters the vertical structure of the kinetic energy.

\section{Conclusions}

We have shown that several dynamical properties of an eddying model are substantially impacted by the presence of wave drag. The modelled bottom kinetic energy is reduced upon insertion of wave drag at both horizontal resolutions studied here $\left(1 / 12^{\circ}\right.$ and $\left.1 / 25^{\circ}\right)$, but is reduced by a larger amount in the higher resolution simulation. The energy dissipation due to quadratic bottom drag is reduced upon insertion of wave drag. However, the total near-bottom energy dissipation (due to wave drag and bottom drag) is greater in the simulations with wave drag than in the simulations having only bottom drag. At the current meter locations examined here, the inclusion of wave drag yields enhanced kinetic energy above about 3000 meters depth and reduced kinetic energy below about 3000 meters depth. The modelled SSH variance and geostrophic SKE are both reduced upon addition of wave drag by more than twice the seasonal variability in each of these diagnostics. The modelled abyssal stratification is also reduced upon insertion of wave drag into the simulations.

We have shown that HYCOM, run at two different horizontal resolutions, is not made worse in a global average, with respect to comparison with observationallyinformed products, when wave drag is inserted. Despite very little change in the 
intensified jet positions, a behavior that contrasts with the atmospheric application of wave drag (Palmer et al., 1986), the SSH variance and geostrophic SKE from the simulations correlate more highly with those inferred from the AVISO product when wave drag is included in HYCOM. The $25 \%, 50 \%$, and $75 \%$ quantiles and geometrically averaged vertical profile of kinetic energy from the simulations come closer to those inferred from the observations at current meter locations when wave drag is added to HYCOM. Our hypothesis is that changes in baroclinic instability are primarily responsible for the dynamical changes noted here, but future studies are required to test this.

Due to the dearth of observational constraints on the closure of oceanic internal lee wave drag, our wave drag parameterization has several deficiencies that could be improved upon. These potential improvements include better justification for the choice of the range of relevant topographic wavenumbers for the internal waves to not be evanescent, relaxing the assumption of small off-diagonal components in the topographic information tensor, using the depth-dependent momentum deposition procedure proposed by Garner (2005) instead of implementing wave drag in the bottom 500 meters, accounting for the role of wave-wave and wave-mean flow interactions in transferring energy, and using a non-local momentum deposition procedure to account for the downstream advection of lee waves. Other potential improvements, such as finding an observationally-informed spectral representation of the roughness of non-abyssal hill regions, and considering the Coriolis force and finiteness of the water column, are discussed in Trossman et al. (2013). In particular, the assumption of finiteness of the water column could have significant consequences. Careful consideration would have to be given regarding how to adapt the Garner (2005) scheme to the oceanic context in order 
for momentum to be conserved (Shepherd and Shaw, 2004; Shaw and Shepherd, 2007). Further, an internal lee wave parameterization that unifies the impact of the generation and breaking of lee waves on both the momentum budget and diapycnal diffusivity is needed. It is suggested here that the deficiency in horizontal model resolution, and the assumption that all of the momentum sink associated with wave drag is in the bottom 500 meters, may be able to explain some of the residual discrepancy between the simulations and observationally-informed products. Future studies will derive and evaluate improved lee wave parameterizations that account for some of the processes described above.

Lastly, longer eddy-resolving simulations are required to fully assess the importance of lee wave parameterizations on both the eddy field and turbulent mixing of the oceanic interior. The relatively small changes seen here at the surface with the inclusion of wave drag do not imply that the surface conditions are insensitive to wave drag in all contexts. It is possible that changes at the surface will be larger when longer model integrations are performed under climate change scenarios (e.g., Melet et al., 2015). Future studies are required to address this.

\section{Acknowledgments}

The authors thank Michael Messina for his computer support at the University of Michigan. D. S. Trossman and B. K. Arbic gratefully acknowledge support from National Science Foundation (NSF) grant OCE-0960820 and Office of Naval Research (ONR) grant N00014-11-1-0487. S. R. Jayne gratefully acknowledges support from NSF grant OCE-0960756. J. G. Richman and A. J. Wallcraft gratefully acknowledge the "6.2 Eddy Resolving Global Ocean Prediction Including Tides" project sponsored by the ONR under program element 
0602435N. Grants of computer time were provided by the Department of Defense (DoD) High Performance Computing Modernization Program and by the National Center for Atmospheric Research (NCAR) Yellowstone university allocations. We would like to acknowledge high-performance computing support from Yellowstone (ark:/85065/d7wd3xhc) provided by NCAR's Computational and Information Systems Laboratory, sponsored by the National Science Foundation. We would also like to acknowledge high-performance computing support from the U.S. Army Engineer Research and Development Center DoD Supercomputing Resource Center in Vicksburg, MS. This is NRL contribution NRL/JA/7320-142433 and has been approved for public release. The output files for the model runs analyzed in this paper are archived at the Department of the Navy Shared Resource Center (DSRC) at the Stennis Space Center. The files stored there can be accessed after obtaining an account at the facility. 
Table 1: The globally integrated energy dissipation rate $\left[\mathrm{TW}=10^{12} \mathrm{~W}\right]$ due to quadratic bottom boundary layer drag (BD) and parameterized topographic internal lee wave drag (WD) from the final year of climatologically forced HYCOM simulations. The simulations are run with and without wave drag at both $1 / 12^{\circ}$ and $1 / 25^{\circ}$ resolutions.

\begin{tabular}{ccccc}
\hline \hline Wave Drag? & Resolution & Year & BD & WD \\
\hline no & $1 / 12^{\circ}$ & 14 & 0.31 & N/A \\
yes & $1 / 12^{\circ}$ & 20 & 0.14 & 0.40 \\
no & $1 / 25^{\circ}$ & 13 & 0.34 & N/A \\
yes & $1 / 25^{\circ}$ & 17 & 0.17 & 0.42 \\
\hline
\end{tabular}

Table 2: The area-averaged values without wave drag (no WD) and with wave drag (WD) as well as the percent differences [in brackets] with the addition of wave drag for several diagnostics: sea surface height variance (SSH var.), geostrophic surface kinetic energy (SKE), and kinetic energy in the bottom 500 meters $\left(\mathrm{KE}_{b o t 500}\right)$. At each resolution, the percent difference is computed as the area-averaged diagnostic with wave drag minus that without wave drag and divided by the area-averaged diagnostic without wave drag. Negative values imply a decrease in the diagnostic, on global average, upon insertion of wave drag.

\begin{tabular}{cccc}
\hline \hline diagnostic & units & $1 / 12^{\circ}$ (no WD, WD) [percent] & $1 / 25^{\circ}$ (no WD, WD) [percent] \\
\hline SSH var. & $\mathrm{m}^{2}$ & $(0.0077,0.0059)(-23.4 \%)$ & $(0.0083,0.0068)(-18.1 \%)$ \\
SKE & $\mathrm{m}^{2} \mathrm{~s}^{-2}$ & $(0.0067,0.0057)(-14.9 \%)$ & $(0.0075,0.0063)(-16.0 \%)$ \\
$\mathrm{KE}_{\text {bot500 }}$ & $\mathrm{m}^{2} \mathrm{~s}^{-2}$ & $(0.0094,0.0076)(-19.1 \%)$ & $(0.019,0.0077)(-59.1 \%)$ \\
\hline
\end{tabular}




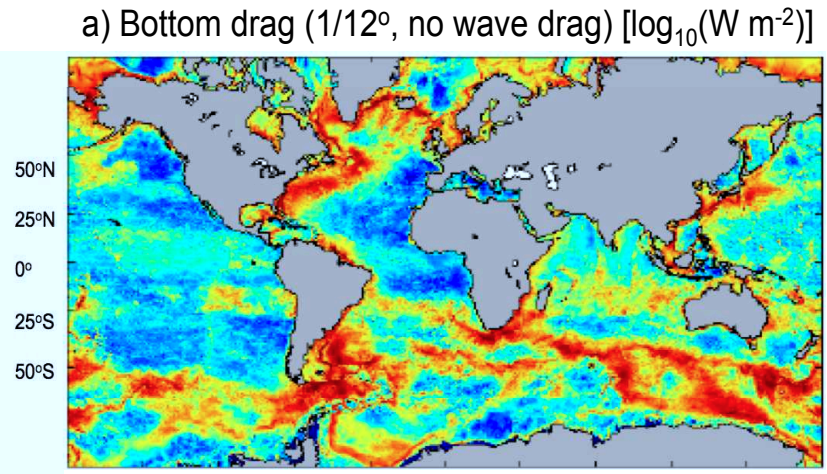

c) Bottom drag $\left(1 / 12^{\circ}\right.$, with wave drag) $\left[\log _{10}\left(\mathrm{~W} \mathrm{~m}^{-2}\right)\right]$

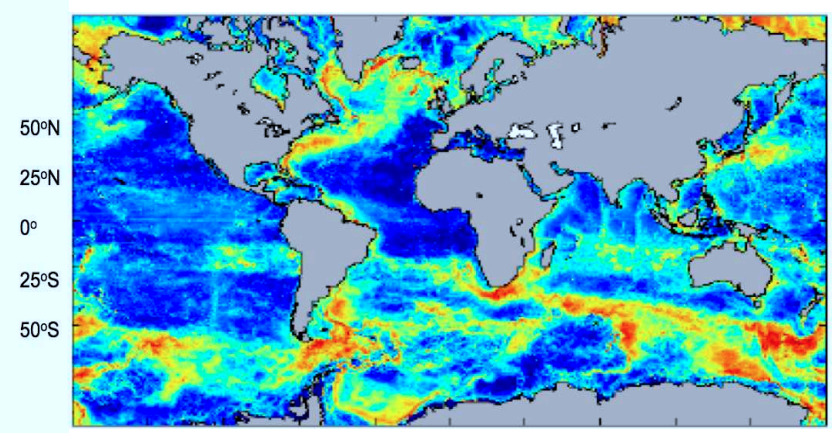

e) Wave drag $\left(1 / 12^{\circ}\right)\left[\log _{10}\left(\mathrm{~W} \mathrm{~m}^{-2}\right)\right]$

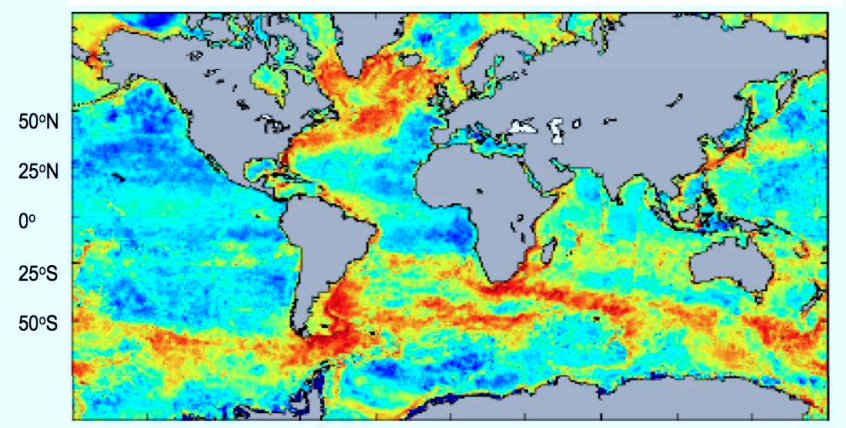

$180^{\circ} \mathrm{W} \quad 144^{\circ} \mathrm{W} \quad 108^{\circ} \mathrm{W} \quad 72^{\circ} \mathrm{W}$ b) Bottom drag $\left(1 / 25^{\circ}\right.$, no wave drag) $\left[\log _{10}\left(\mathrm{~W} \mathrm{~m}^{-2}\right)\right]$

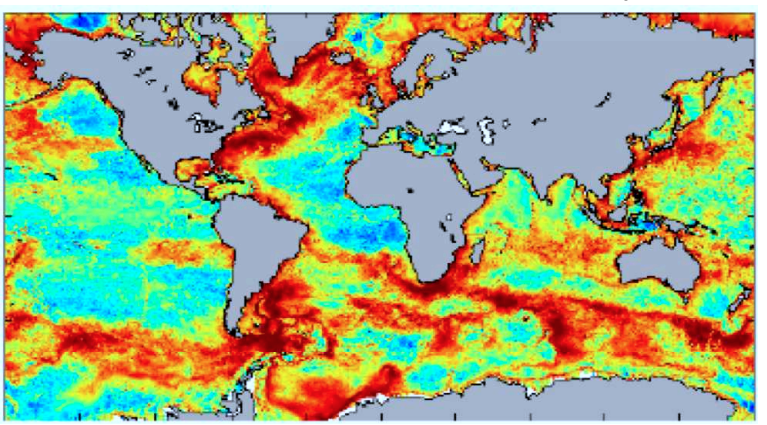

d) Bottom drag $\left(1 / 25^{\circ}\right.$, with wave drag) $\left[\log _{10}\left(\mathrm{~W} \mathrm{~m}^{-2}\right)\right]$

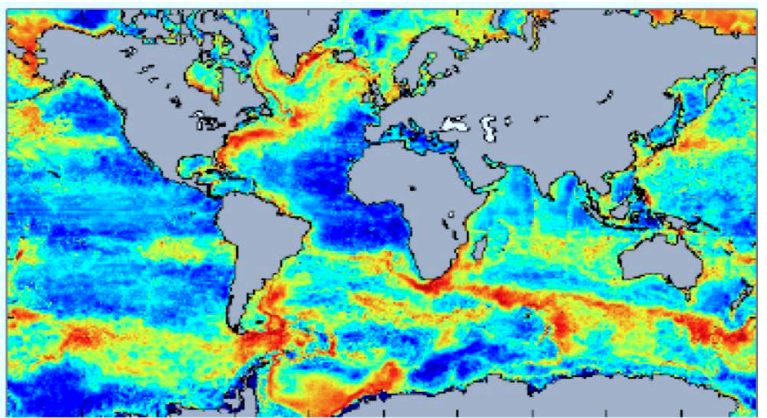

f) Wave drag $\left(1 / 25^{\circ}\right)\left[\log _{10}\left(\mathrm{~W} \mathrm{~m}^{-2}\right)\right]$

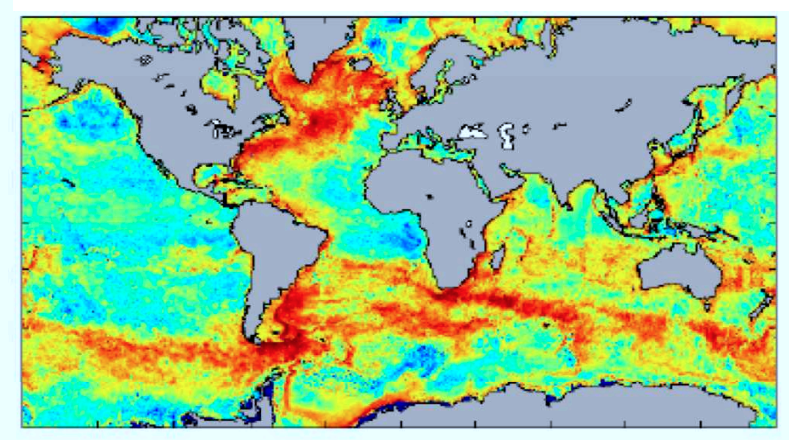

$36^{\circ} \mathrm{W} \quad 0^{\circ} \quad 36^{\circ} \mathrm{E} \quad 7^{\circ} \mathrm{E} \quad 108^{\circ} \mathrm{E} \quad 144^{\circ} \mathrm{E} \quad 180^{\circ} \mathrm{W}$

Figure 1: The base 10 logarithm of the energy dissipation (units in $\mathrm{W} \mathrm{m}^{-2}$ ) associated with (ad) bottom drag and (e-f) wave drag in the (a, c, and e) $1 / 12^{\circ}$ HYCOM and (b, d, and f) $1 / 25^{\circ}$ HYCOM simulations (a-b) without wave drag and (c-f) with wave drag. An average over the final year of the model simulations has been performed. 
a)

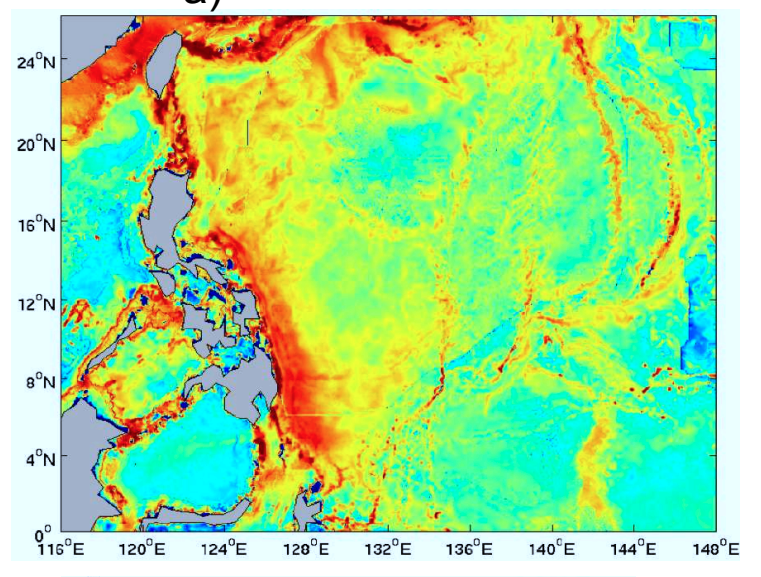

c)

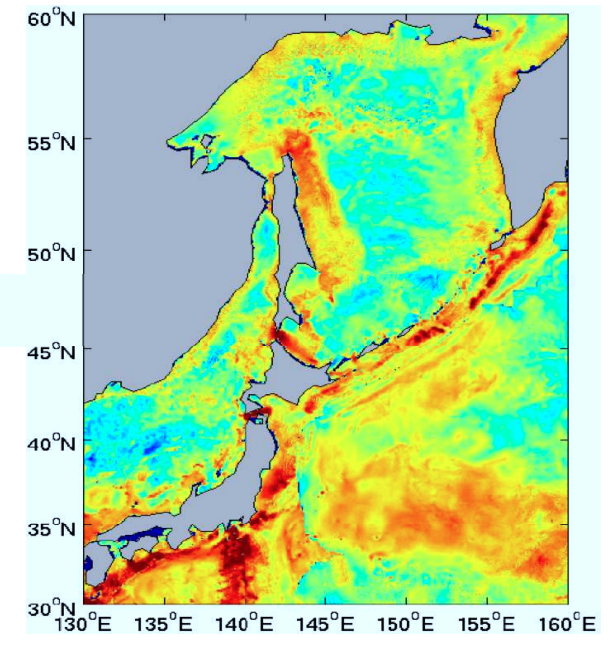

d) b)
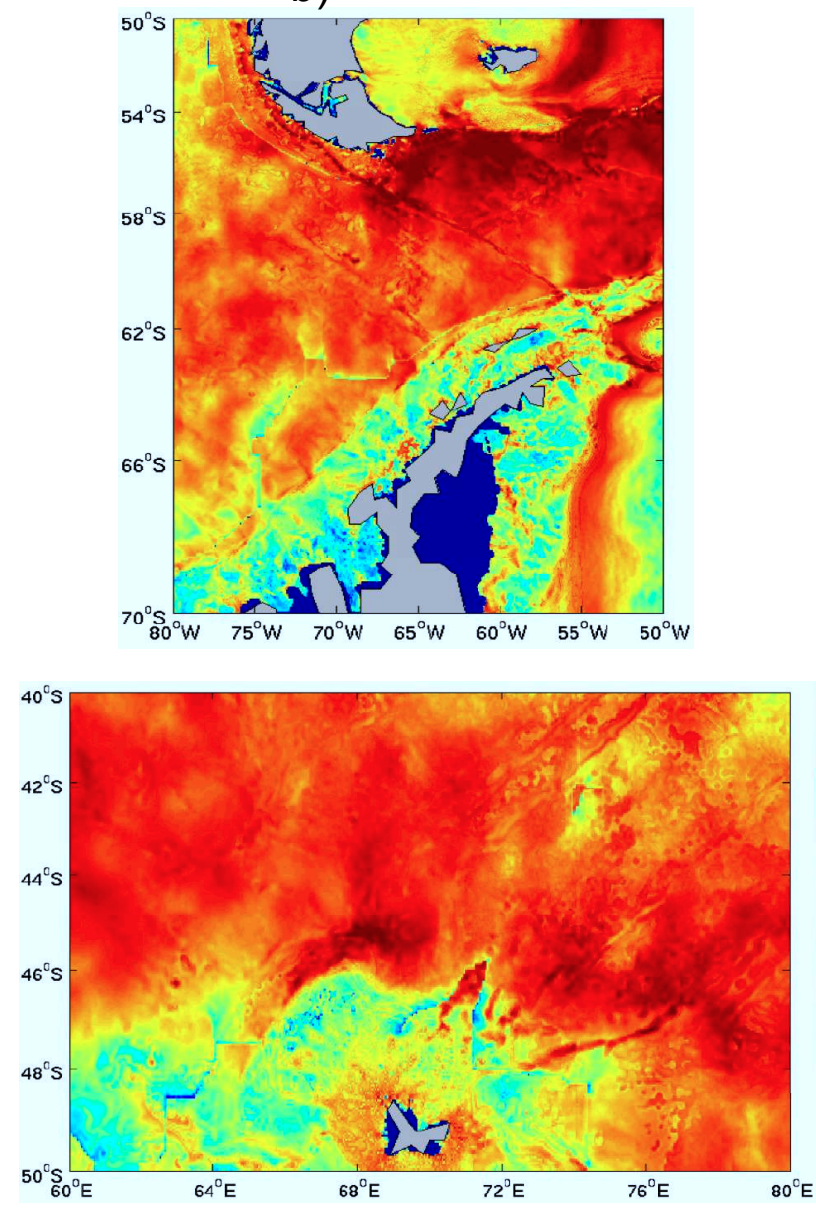

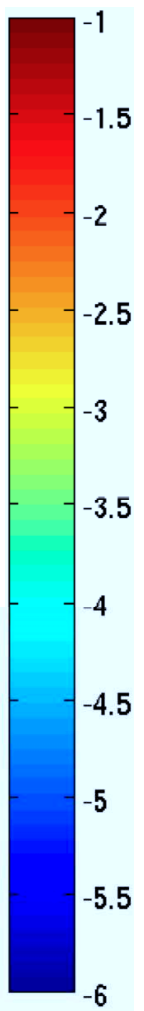

Figure 2: The base 10 logarithm of the energy dissipation (units in $\mathrm{W} \mathrm{m}^{-2}$ ) associated with wave drag in the (a) FLEAT (FLow Encountering Abrupt Topography), (b) DIMES (Diapycnal and Isopycnal Mixing Experiment in the Southern Ocean), (c) KESS (Kuroshio Extension Study System), and (d) SOFine (Southern Ocean Finestructure) observational campaign regions in the $1 / 25^{\circ}$ HYCOM simulation. An average over the final year of the model simulations has been performed. 
a) KE bottom 500 meters $\left(1 / 12^{\circ}\right.$, no wave drag) $\left[\log _{10}\left(\mathrm{~m}^{2} \mathrm{~s}^{-2}\right)\right]$

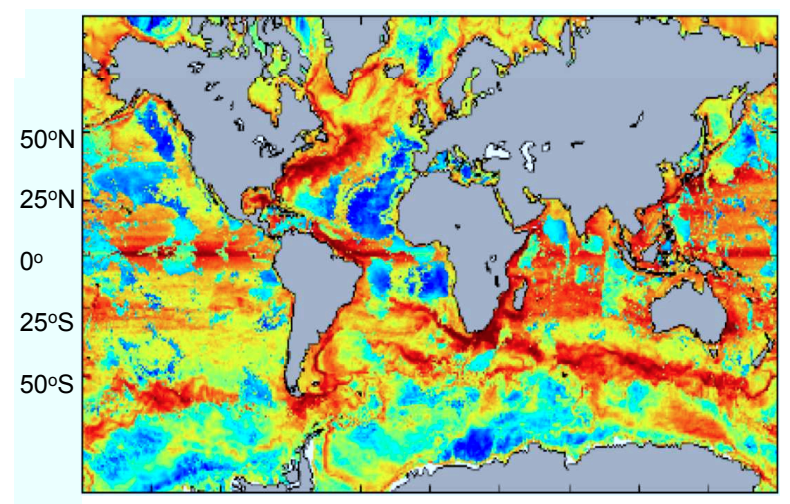

c) KE bottom 500 meters $\left(1 / 12^{\circ}\right.$, with wave drag) $\left[\log _{10}\left(\mathrm{~m}^{2} \mathrm{~s}^{-2}\right)\right]$

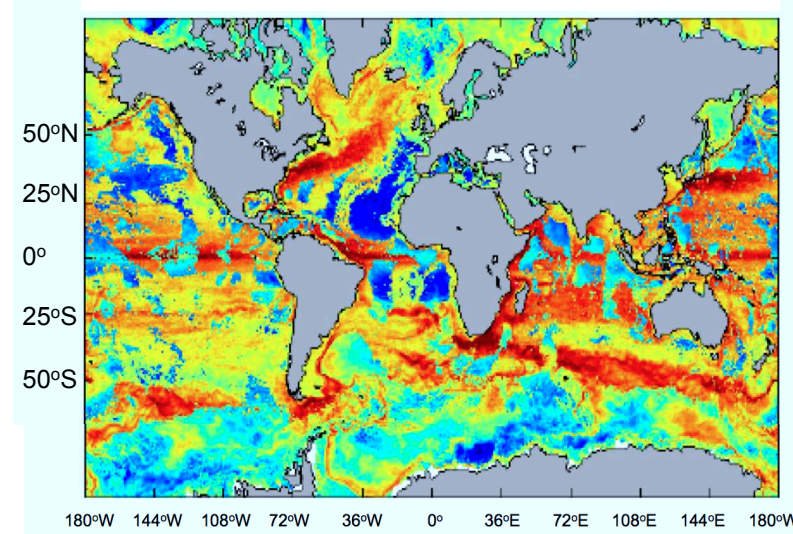

b) KE bottom 500 meters $\left(1 / 25^{\circ}\right.$, no wave drag) $\left[\log _{10}\left(\mathrm{~m}^{2} \mathrm{~s}^{-2}\right)\right]$

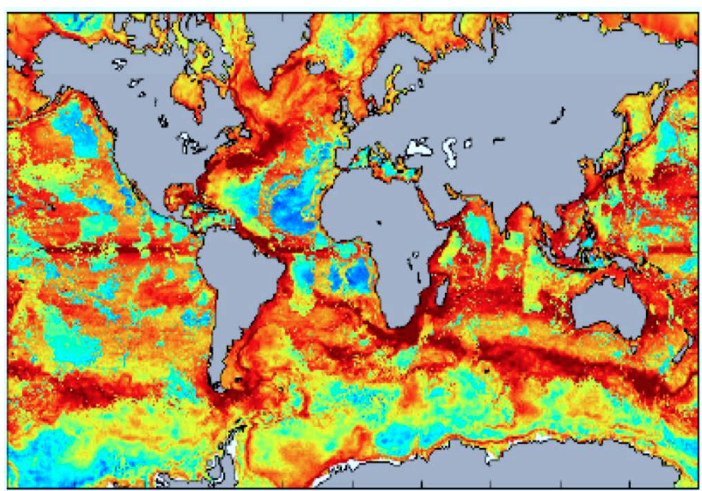

d) KE bottom 500 meters $\left(1 / 25^{\circ}\right.$, with wave drag) $\left[\log _{10}\left(\mathrm{~m}^{2} \mathrm{~s}^{-2}\right)\right]$

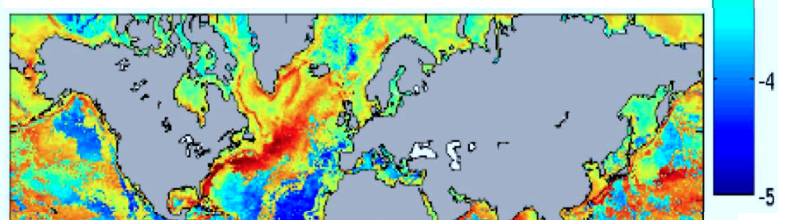

Figure 3: The base 10 logarithm of the kinetic energies (units in $\mathrm{m}^{2} \mathrm{~s}^{-2}$ ) averaged over the bottom 500 meters from the (a) $1 / 12^{\circ} \mathrm{HYCOM}$ simulation without wave drag, (b) $1 / 25^{\circ} \mathrm{HYCOM}$ simulation without wave drag, (c) $1 / 12^{\circ} \mathrm{HYCOM}$ simulation with wave drag, and (d) $1 / 25^{\circ} \mathrm{HYCOM}$ simulation with wave drag. An average over the final year of the model simulations has been performed. 
a) Bottom drag dissipation (without-with wave drag) [W $\left.\mathrm{m}^{-2}\right]$
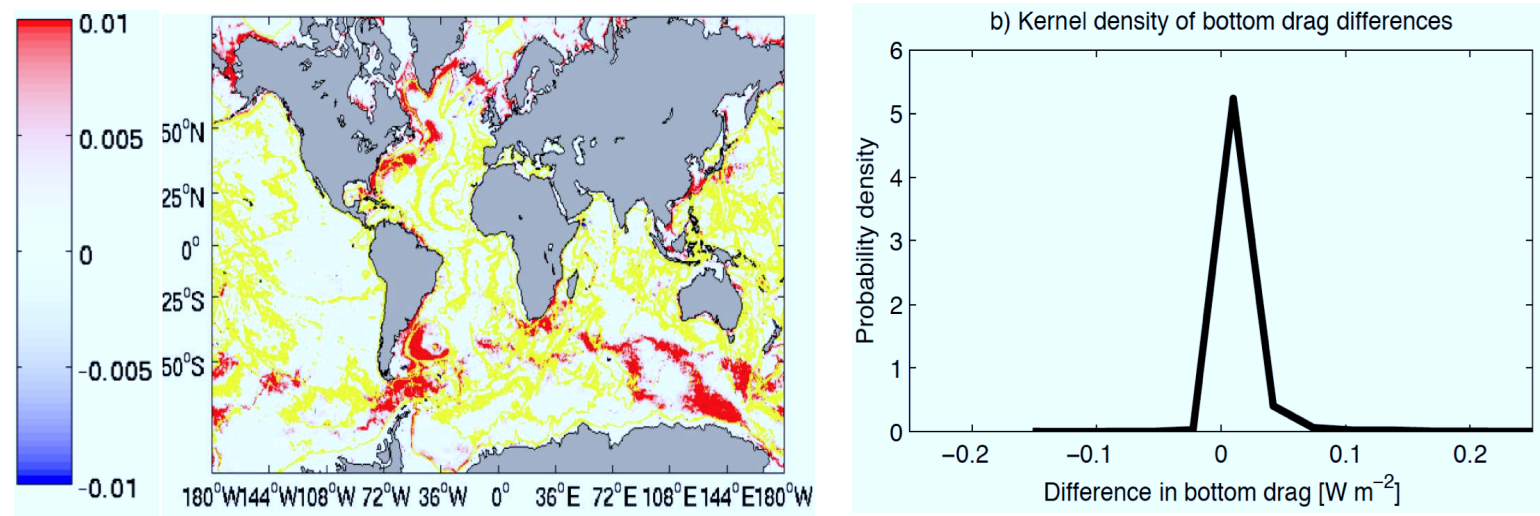

c) $\mathrm{KE}^{3 / 2}$ (without-with wave drag) $\left[\mathrm{m}^{3} \mathrm{~s}^{-3}\right]$
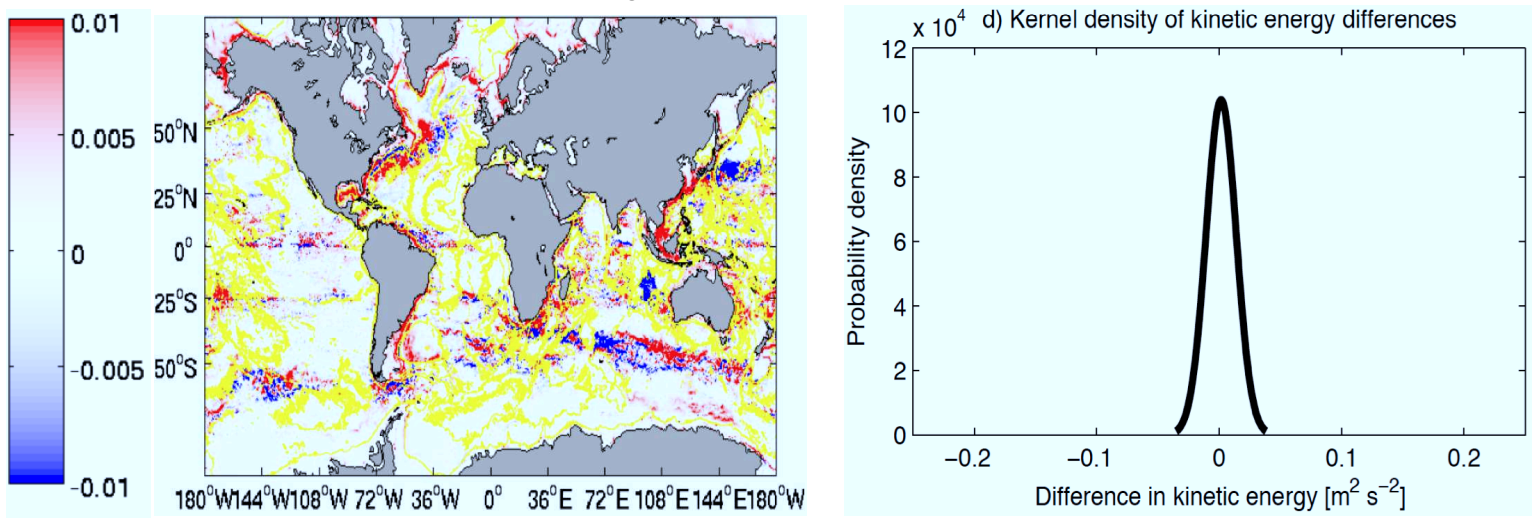

Figure 4: (a) The differences in energy dissipation (units in $\mathrm{W} \mathrm{m}^{-2}$ ) associated with bottom drag and (c) the differences in kinetic energy (KE) averaged over the bottom 500 meters to the $3 / 2$ power (units in $\mathrm{m}^{3} \mathrm{~s}^{-3}$ ), both from the $1 / 12^{\circ} \mathrm{HYCOM}$ without minus with wave drag simulations. In yellow are the underlying topographic contours. Also shown are kernel densities of (b) the differences in energy dissipation associated with bottom drag and (d) the differences in KE, both from the $1 / 12^{\circ} \mathrm{HYCOM}$ without minus with wave drag simulations. An average over the final year of the model simulations has been performed. 
a) SSH variance $\left[\log _{10}\left(\mathrm{~m}^{2}\right)\right] 1 / 25^{\circ} \mathrm{HYCOM}$, no wave drag

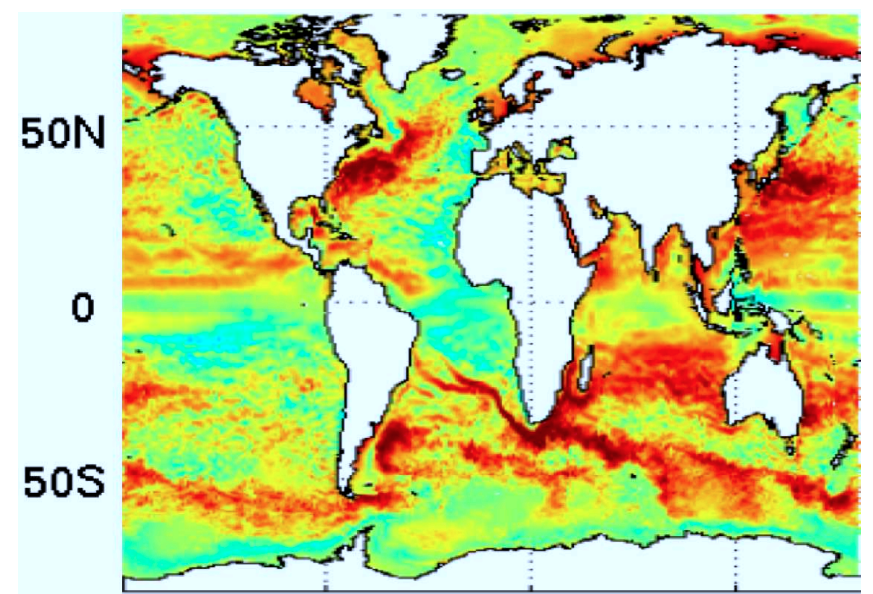

b) SSH variance $\left[\log _{10}\left(\mathrm{~m}^{2}\right)\right] 1 / 25^{\circ} \mathrm{HYCOM}$, wave drag

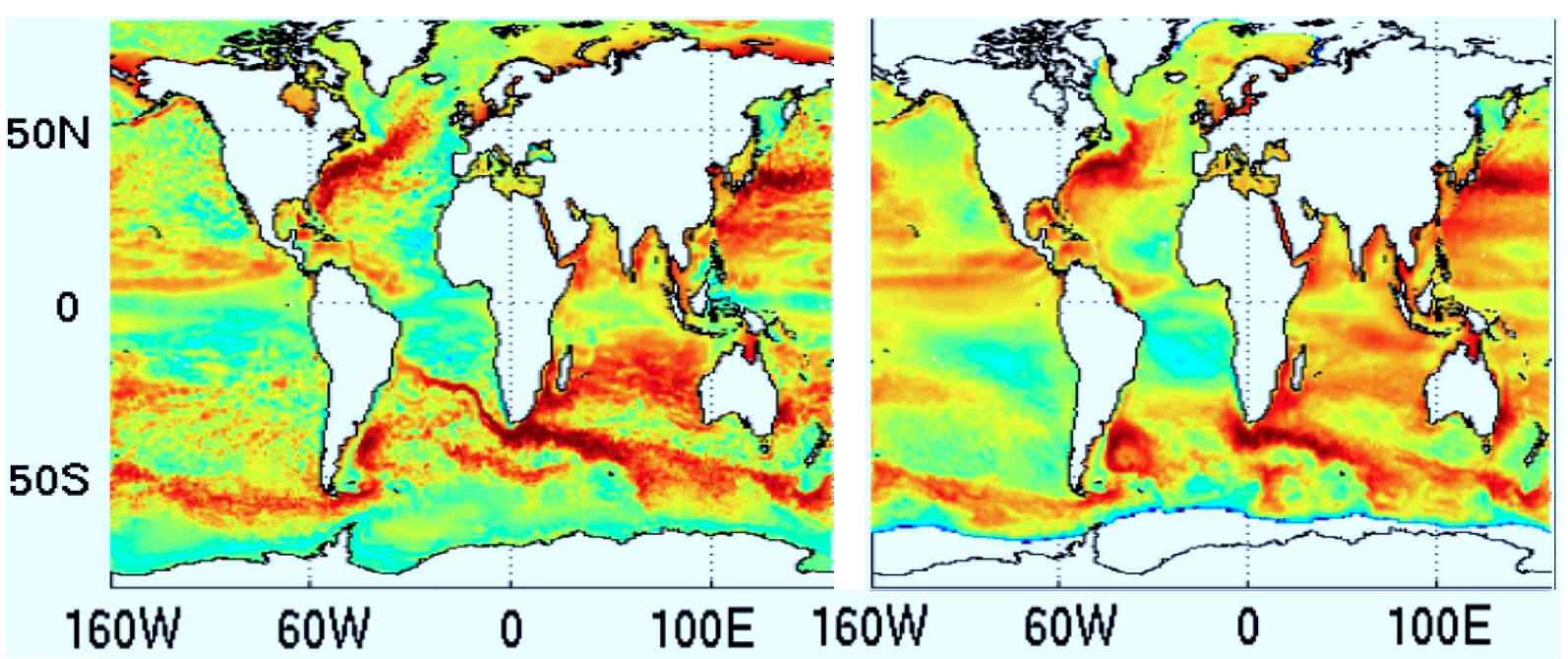

Figure 5: The base 10 logarithm of the variance (units in $\mathrm{m}^{2}$ ) of the sea surface heights, or $\mathrm{SSH}$, from the (a) $1 / 25^{\circ}$ HYCOM without wave drag simulation, (b) $1 / 25^{\circ}$ HYCOM with wave drag simulation, and (c) AVISO product. The modelled SSH variances are calculated from daily averages and then averaged over the final year of each model simulation. The SSH variances from AVISO are averaged over 1992-2008. 
a) SSH var. diff. [m²] 1/12 ${ }^{\circ}$ HYCOM, with-no wave drag

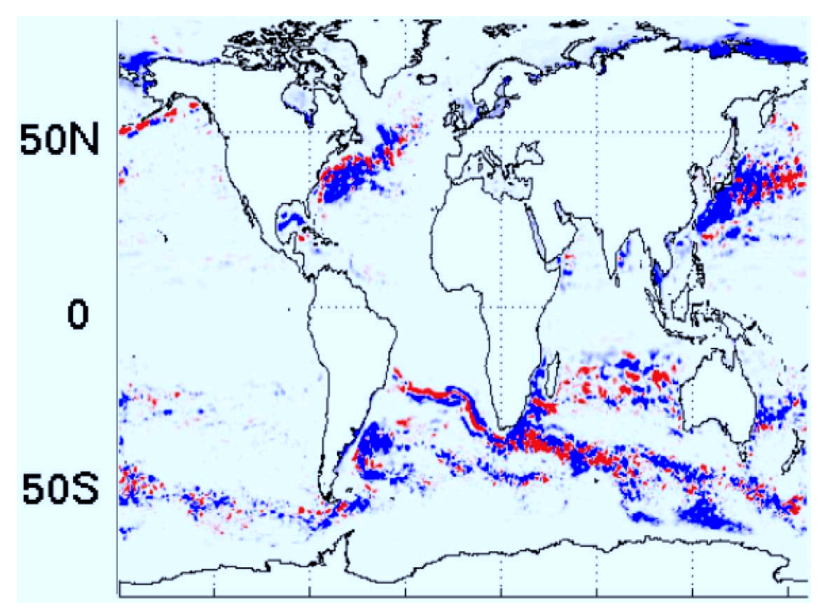

c) SSH var. diff. [m²] 1/250-1/12 ${ }^{\circ}$ HYCOM, no wave drag

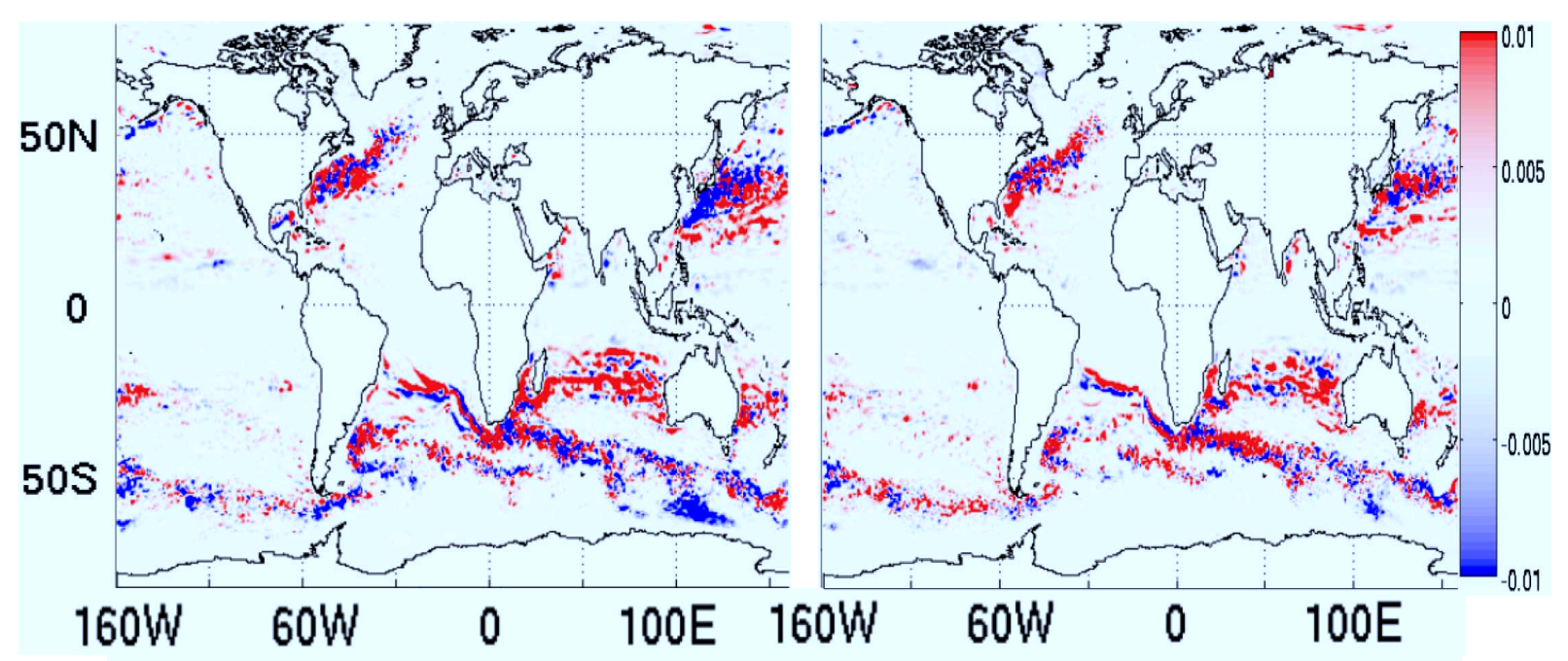

Figure 6: The differences in the variance of the sea surface heights, or SSH, (units in $\mathrm{m}^{2}$ ) between: (a) $1 / 12^{\circ}$ HYCOM with minus without wave drag, (b) $1 / 25^{\circ}$ HYCOM with minus without wave drag, (c) $1 / 25^{\circ}$ minus $1 / 12^{\circ} \mathrm{HYCOM}$ without wave drag, and (d) $1 / 25^{\circ}$ minus $1 / 12^{\circ} \mathrm{HYCOM}$ with wave drag. The SSH variances are calculated from daily averages and then averaged over the final year of each model simulation. 
a) Geostrophic SKE $\left[\log _{10}\left(\mathrm{~m}^{2} \mathrm{~s}^{-2}\right)\right] 1 / 25^{\circ} \mathrm{HYCOM}$, no wave drag

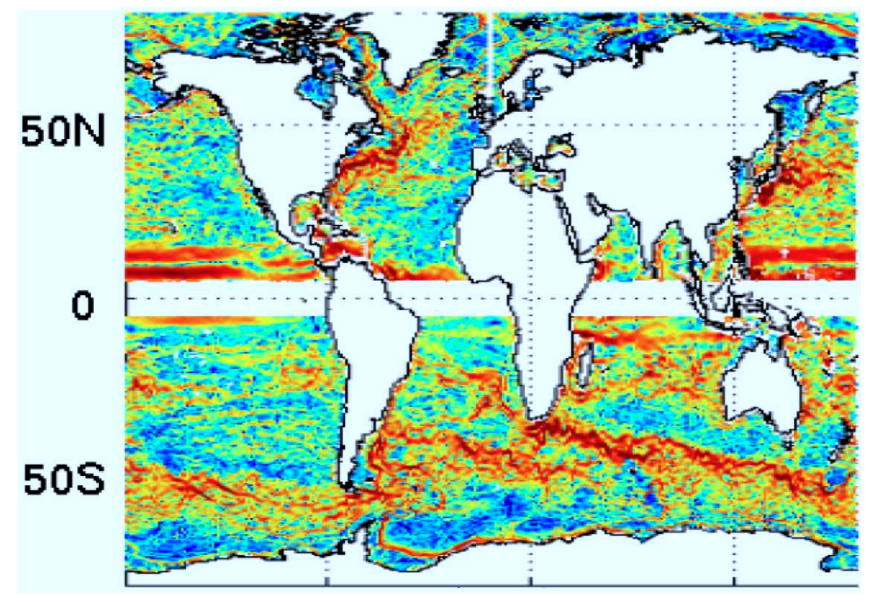

b) Geostrophic SKE $\left[\log _{10}\left(m^{2} s^{-2}\right)\right] 1 / 25^{\circ}$ HYCOM, wave drag

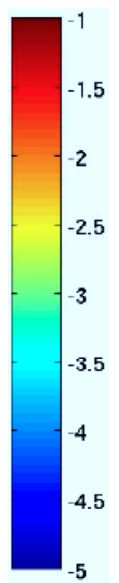

c) Geostrophic SKE $\left[\log _{10}\left(\mathrm{~m}^{2} \mathrm{~s}^{-2}\right)\right]$ AVISO

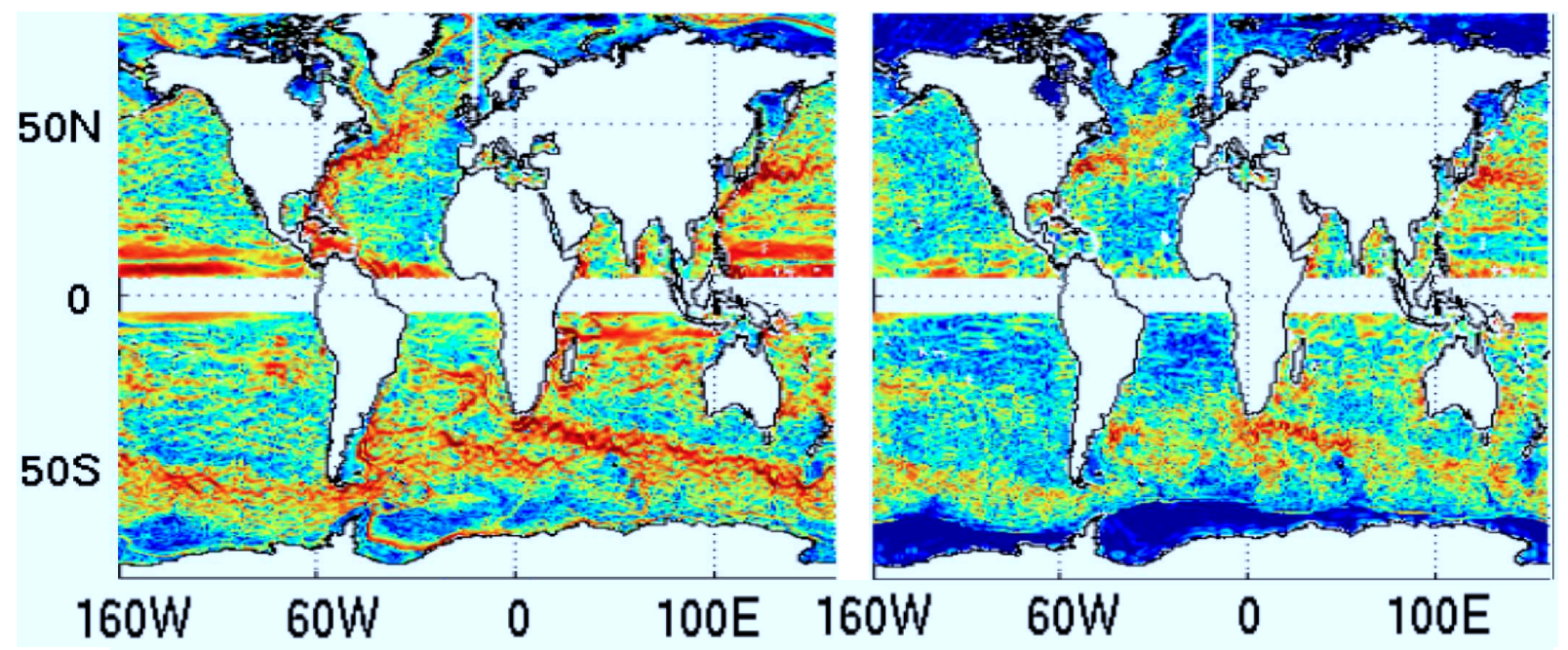

Figure 7: As in Fig. 5, but for the base 10 logarithm of the geostrophic surface kinetic energy (SKE) (units in $\mathrm{m}^{2} \mathrm{~s}^{-2}$ ). 


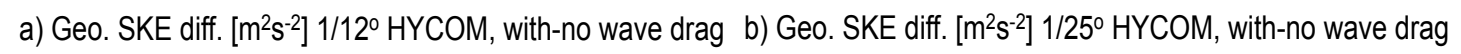
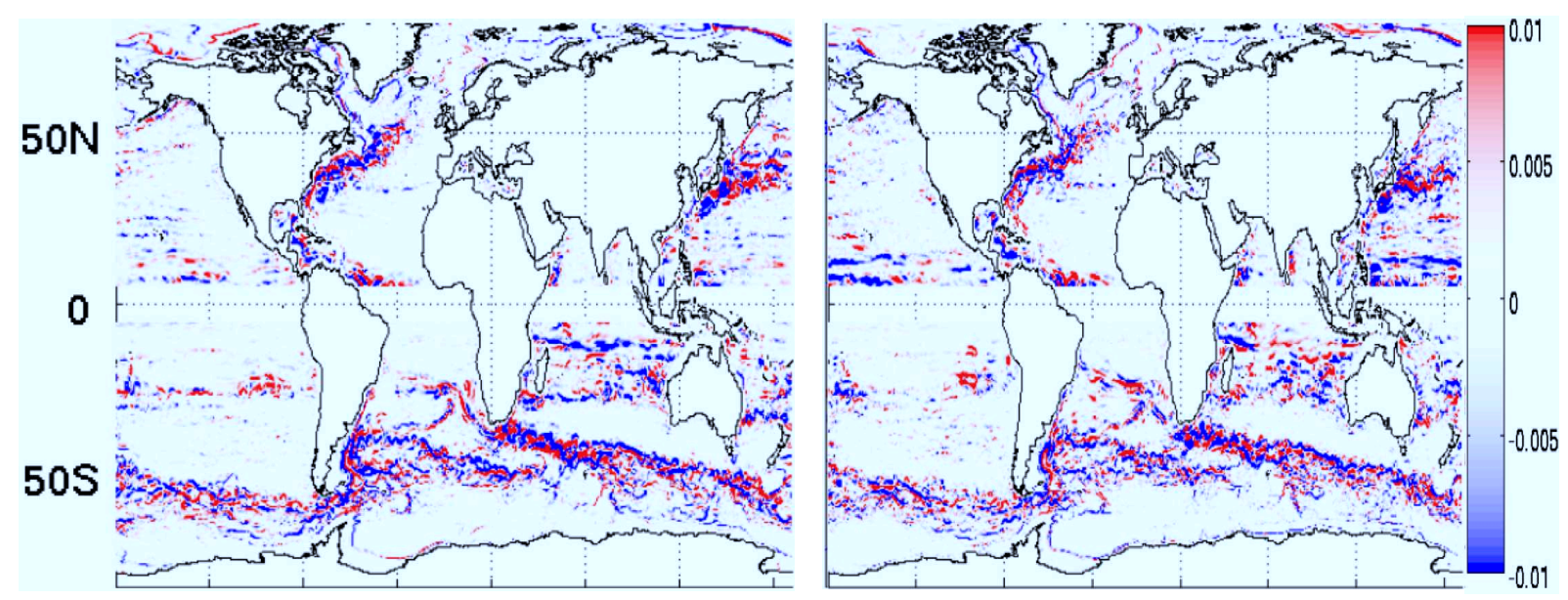

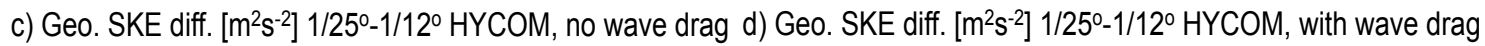

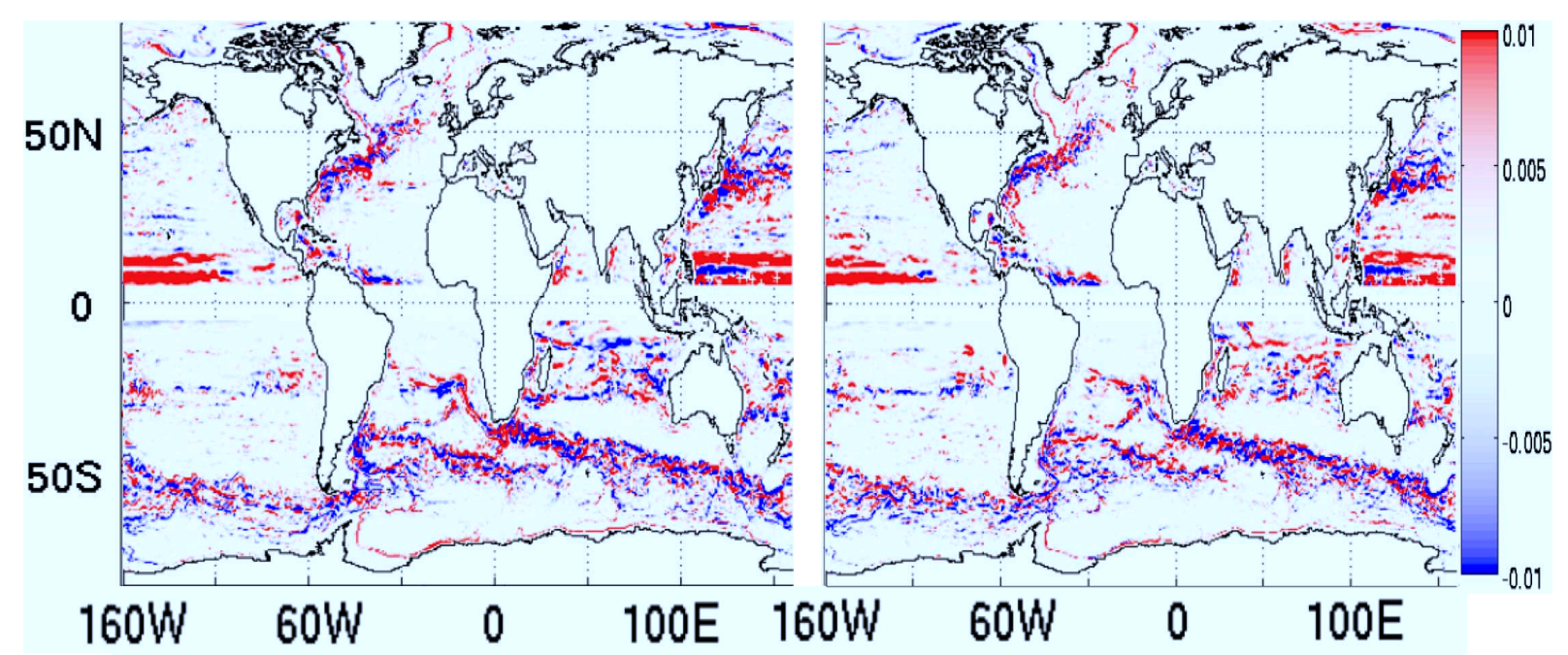

Figure 8: As in Fig. 6, but for the differences in geostrophic surface kinetic energy (SKE) (units in $\mathrm{m}^{2} \mathrm{~s}^{-2}$ ). 
a) $\mathrm{SSH}$ var. changes with same sign when wave drag is added

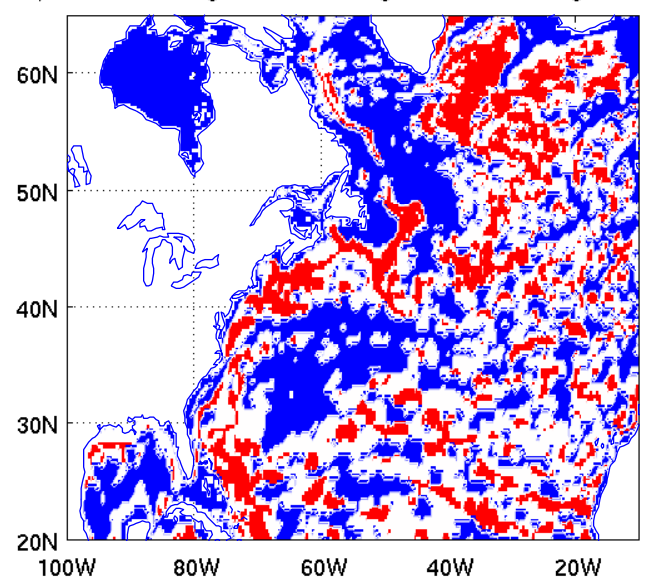

c) SKE changes with same sign when wave drag is added

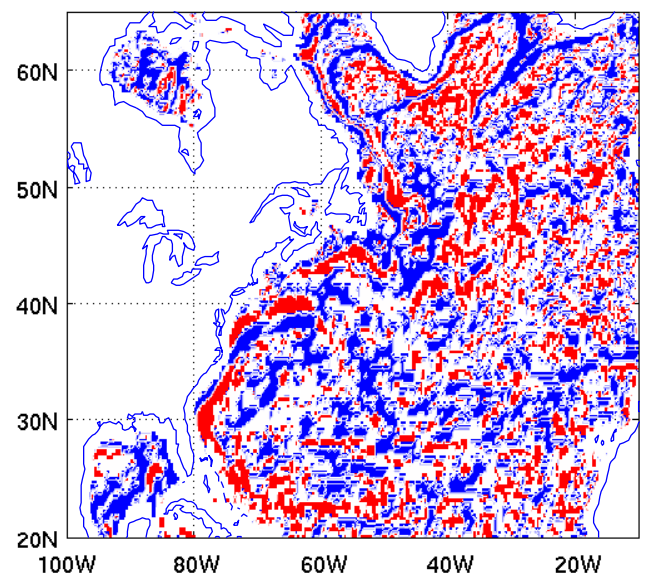

b) $\mathrm{SSH}$ var. changes with same sign when wave drag is added

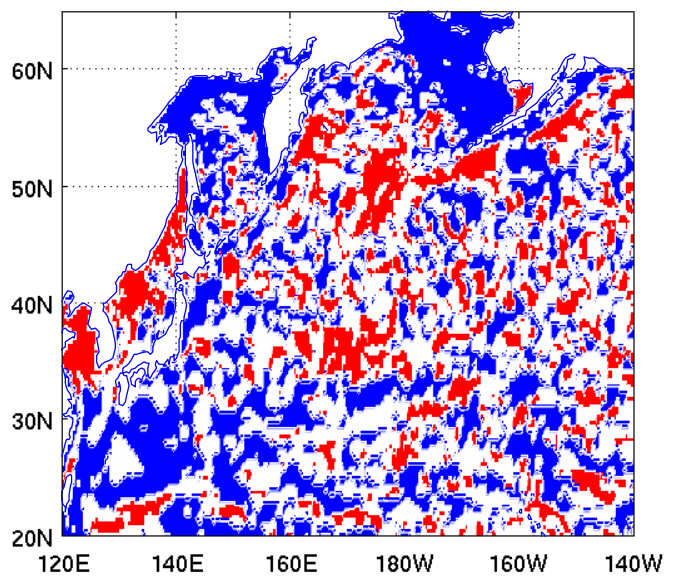

d) SKE changes with same sign when wave drag is added

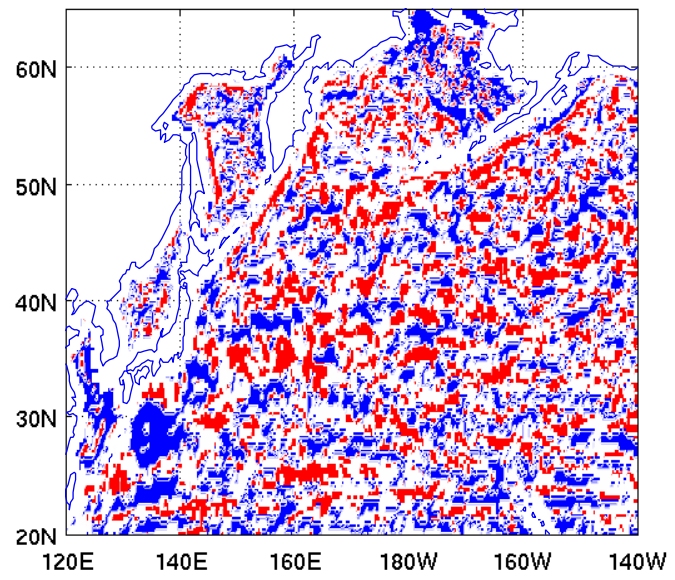

Figure 9: The locations where the sea surface height variance (SSH var.) and geostrophic surface kinetic energy (SKE) change with the same sign when wave drag is inserted into both the $1 / 12^{\circ}$ and $1 / 25^{\circ}$ HYCOM simulations. The blue (red) regions indicate that the SSH variance (a-b) or geostrophic SKE (c-d) are reduced (increased) upon insertion of wave drag in the North Atlantic Ocean (a and c) or the North Pacific Ocean (b and d). The SSH variances and geostrophic SKEs are calculated from daily averages and then averaged over the final year of each model simulation. 


\section{Current meter locations}

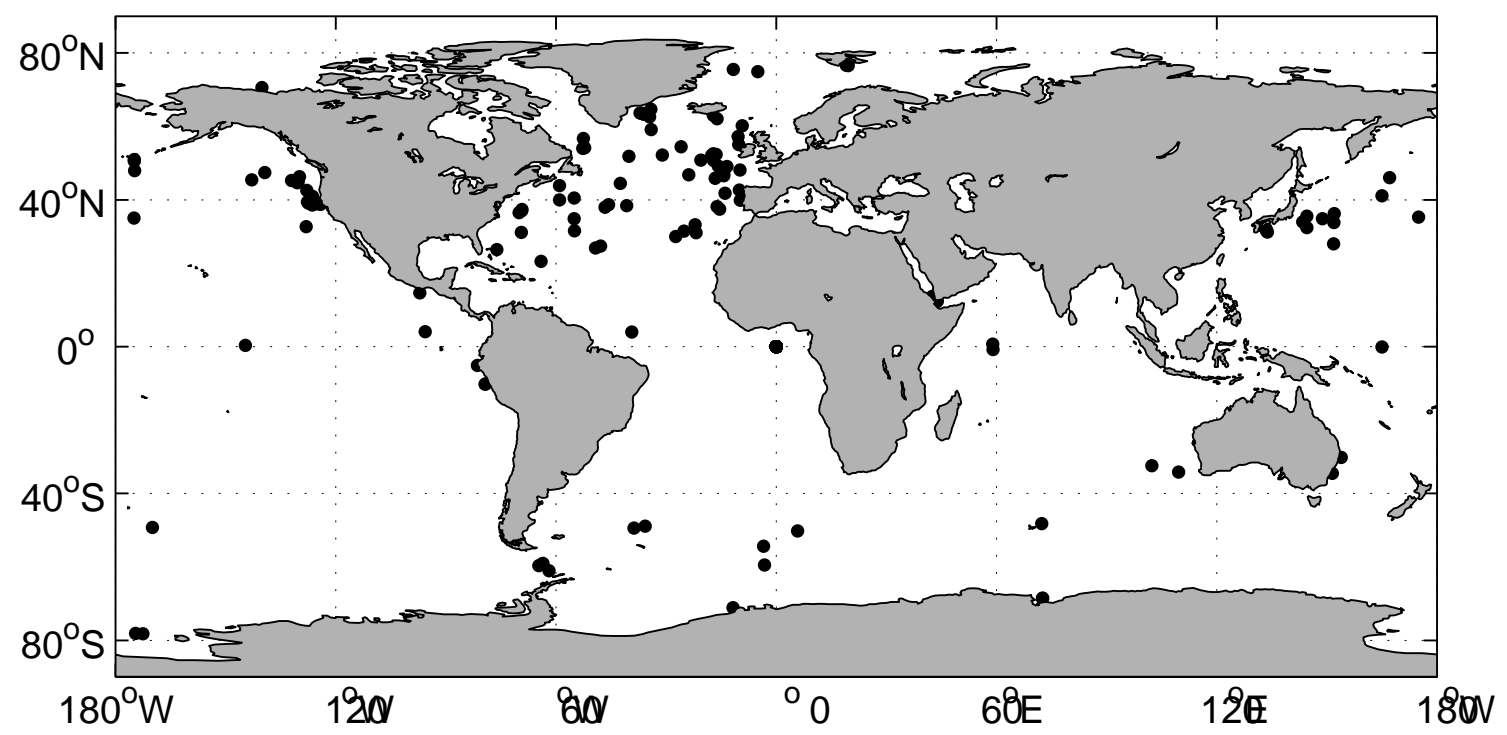

Figure 10: The horizontal locations (black circles) of the current meter observations used in this study. Shown here are the locations of the moorings having at least one current meter record that is one-half year or more in duration. 
a) $1 / 12^{\circ} \mathrm{HYCOM}$ (no wave drag)

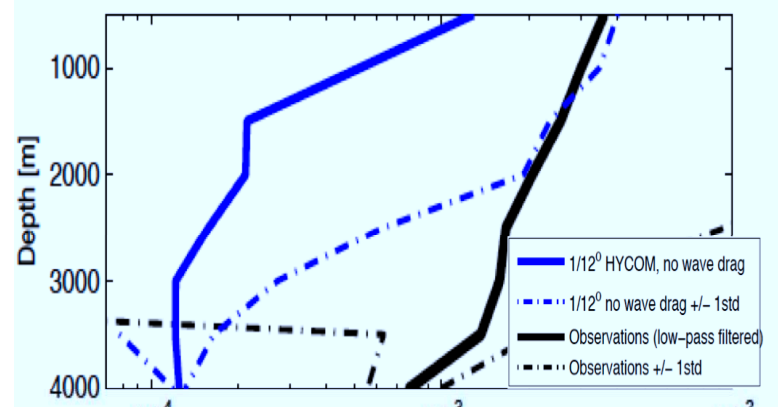

$10^{-4}$

$10^{-3}$
Kinetic energy $\left[\mathrm{m}^{2} \mathrm{~s}^{-2}\right]$

c) $1 / 25^{\circ}$ HYCOM (no wave drag)

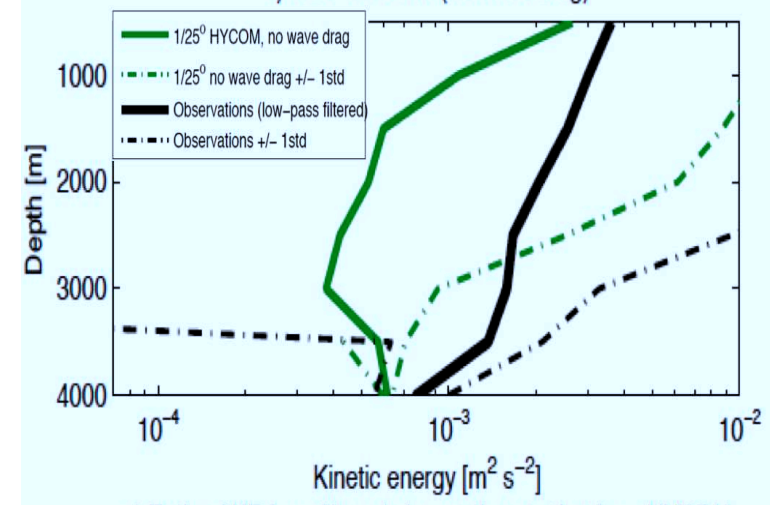

e) Ratio of KE from filtered observations to that from HYCOM

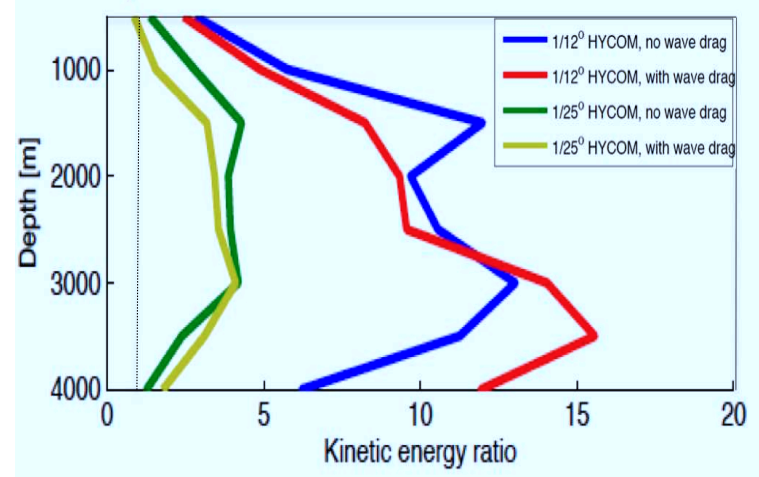

b) $1 / 12^{\circ} \mathrm{HYCOM}$ (with wave drag)

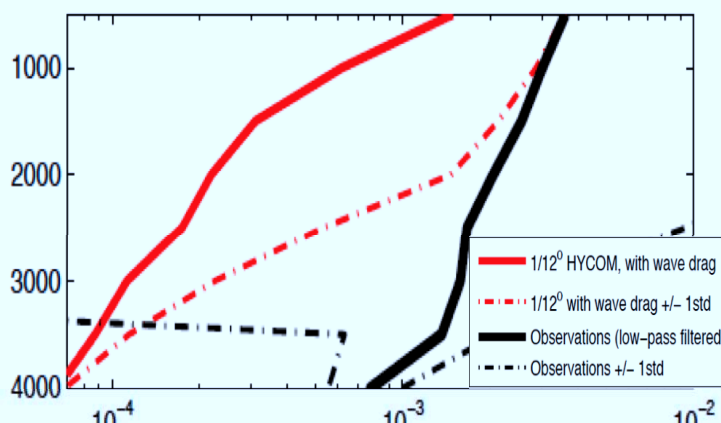

$10^{-3}$

Kinetic energy $\left[\mathrm{m}^{2} \mathrm{~s}^{-2}\right]$

d) $1 / 25^{\circ} \mathrm{HYCOM}$ (with wave drag)
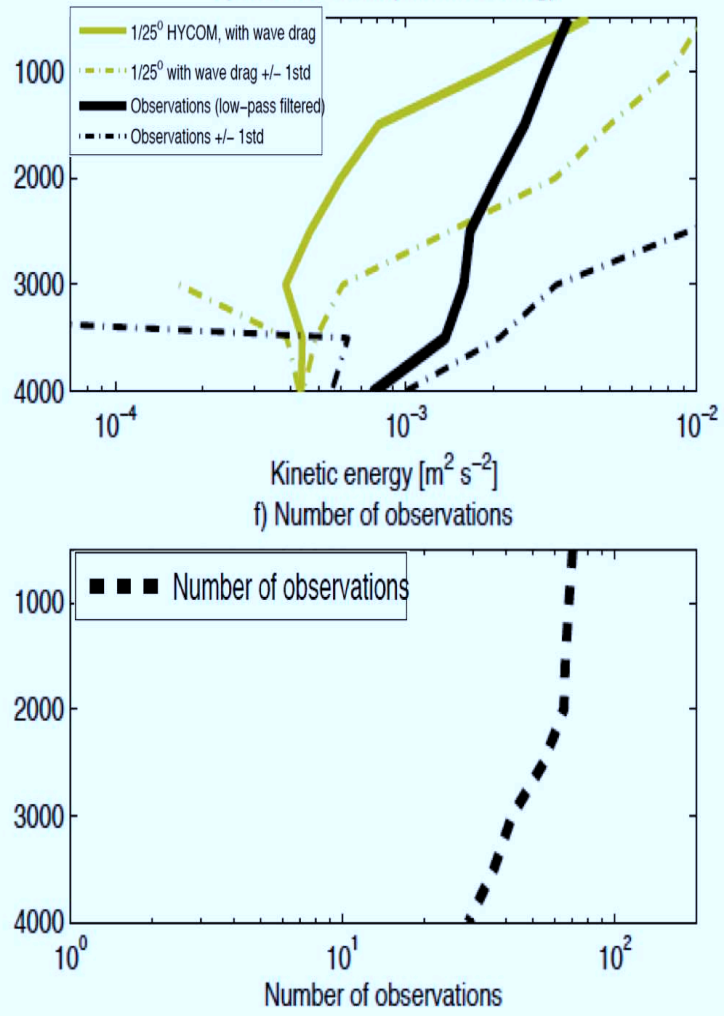

Figure 11: The horizontal location averaged kinetic energies (units in $\mathrm{m}^{2} \mathrm{~s}^{-2}$ and put into 500 meter depth bins) from the current meter database (thick solid black) shown alongside those from (a) $1 / 12^{\circ}$ HYCOM without wave drag (blue), (b) $1 / 12^{\circ}$ HYCOM with wave drag (red), (c) $1 / 25^{\circ}$ HYCOM without wave drag (green), and (d) $1 / 25^{\circ}$ HYCOM with wave drag (gold). An average over the final year of the model simulations and over the entire length of the observational time series has been performed. Flanking the kinetic energy profiles are the $\pm_{1}$ spatial geometric standard deviation of the kinetic energy at each depth level (dash-dotted curves). Also shown are (e) the ratios of the average kinetic energies of the low-pass filtered observations to the $1 / 12^{\circ}$ HYCOM without wave drag (blue), $1 / 12^{\circ} \mathrm{HYCOM}$ with wave drag (red), $1 / 25^{\circ}$ HYCOM without wave drag (green), and $1 / 25^{\circ}$ HYCOM with wave drag (gold) as functions of depth. The dotted line in panel e indicates agreement between the modelled kinetic energies and the filtered observations. (f) The number of locations used for each depth bin average. 
a) SSH var. diff. [m²] 1/250 HYCOM, no wave drag-AVISO b) SSH var. diff. [m²] 1/250 HYCOM, with wave drag-AVISO
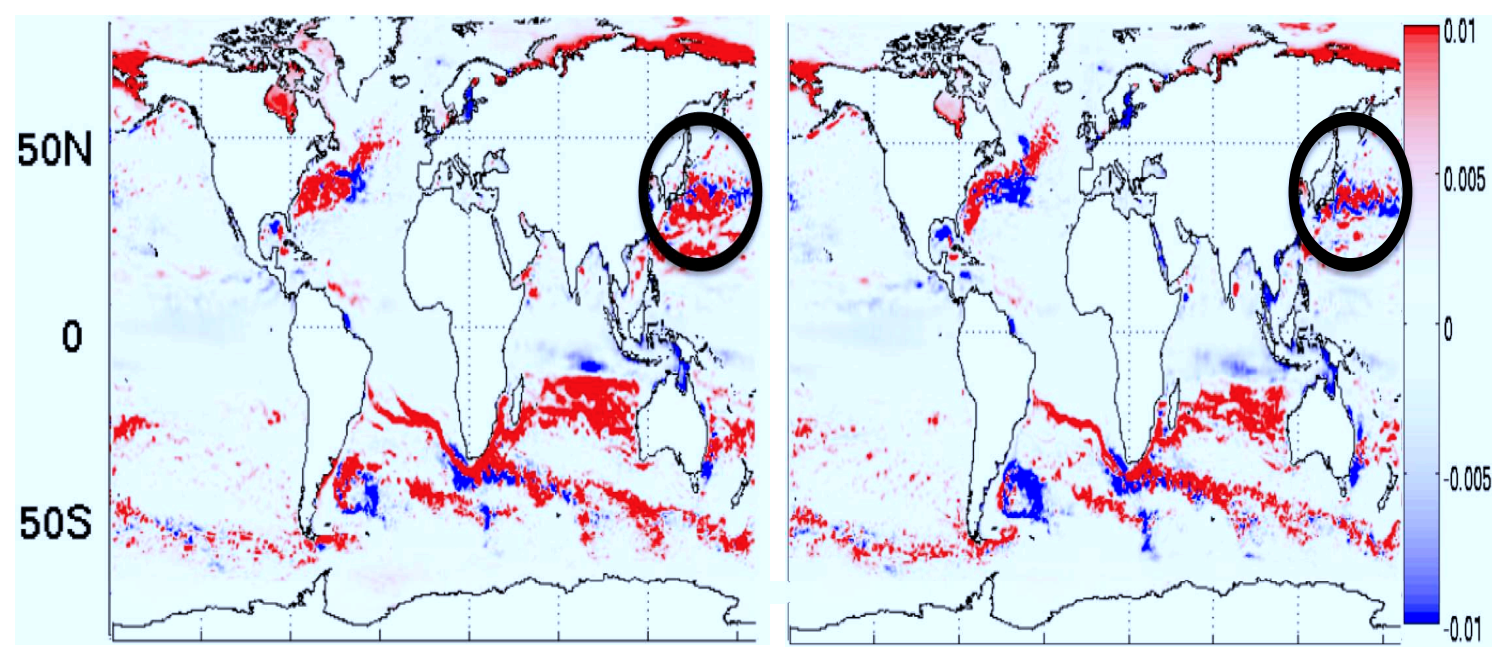

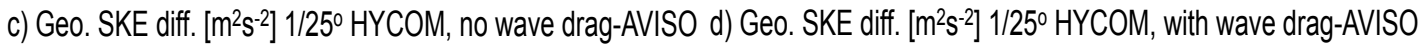

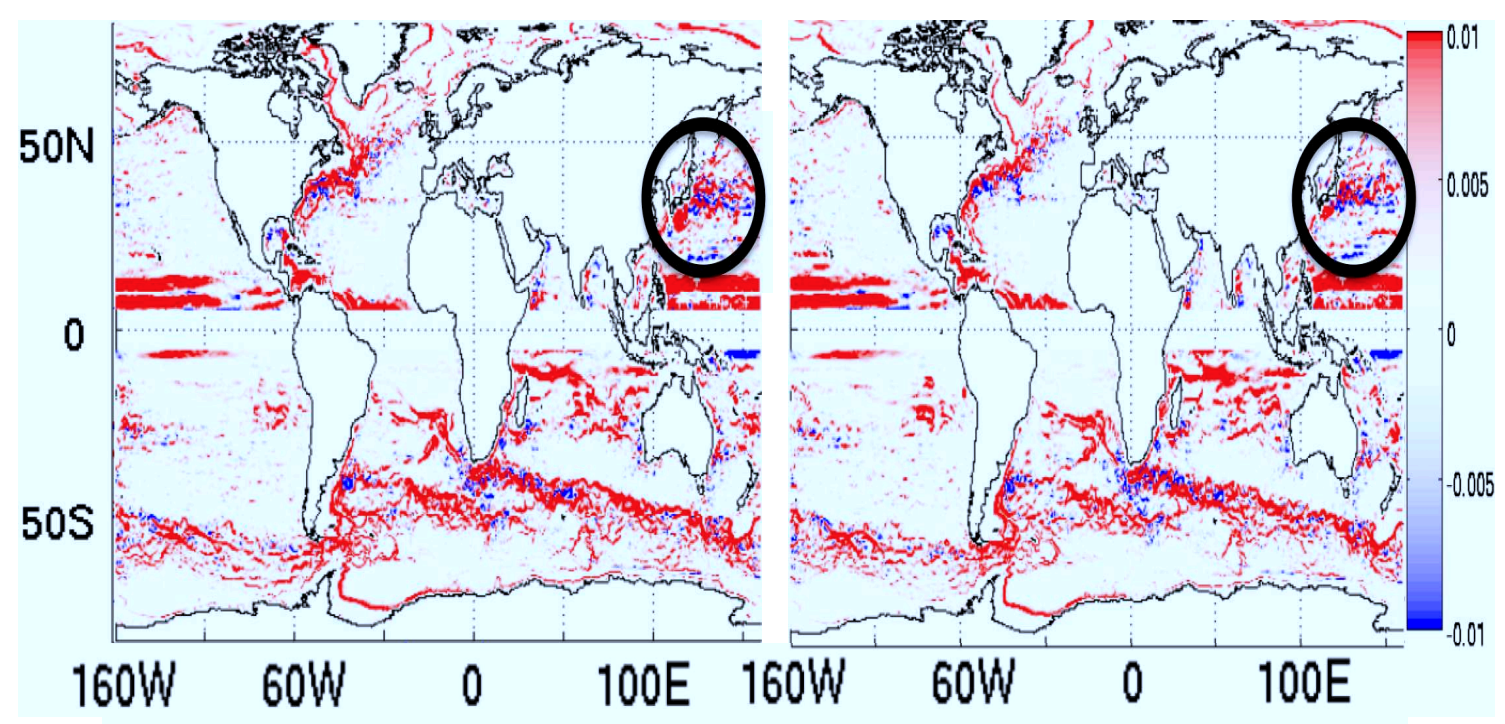

Figure 12: (a-b) Global maps of the differences between the sea surface height (SSH) variance (units in $\mathrm{m}^{2}$ ) from: (a) $1 / 25^{\circ}$ HYCOM without wave drag minus AVISO and (b) $1 / 25^{\circ} \mathrm{HYCOM}$ with wave drag minus AVISO. (c-d) Global maps of the differences betweeen the geostrophic surface kinetic energy (SKE) (units in $\mathrm{m}^{2} \mathrm{~s}^{-2}$ ) from: (c) $1 / 25^{\circ} \mathrm{HYCOM}$ without wave drag minus AVISO and (d) $1 / 25^{\circ}$ HYCOM with wave drag minus AVISO. Shown are averages over the final year of each model simulation minus 1992-2008 AVISO averages. The Kuroshio Extension region is circled in black in each subplot. 
a) Sea surface height $(\mathrm{SSH})$ variance $\left[\mathrm{m}^{2}\right]$

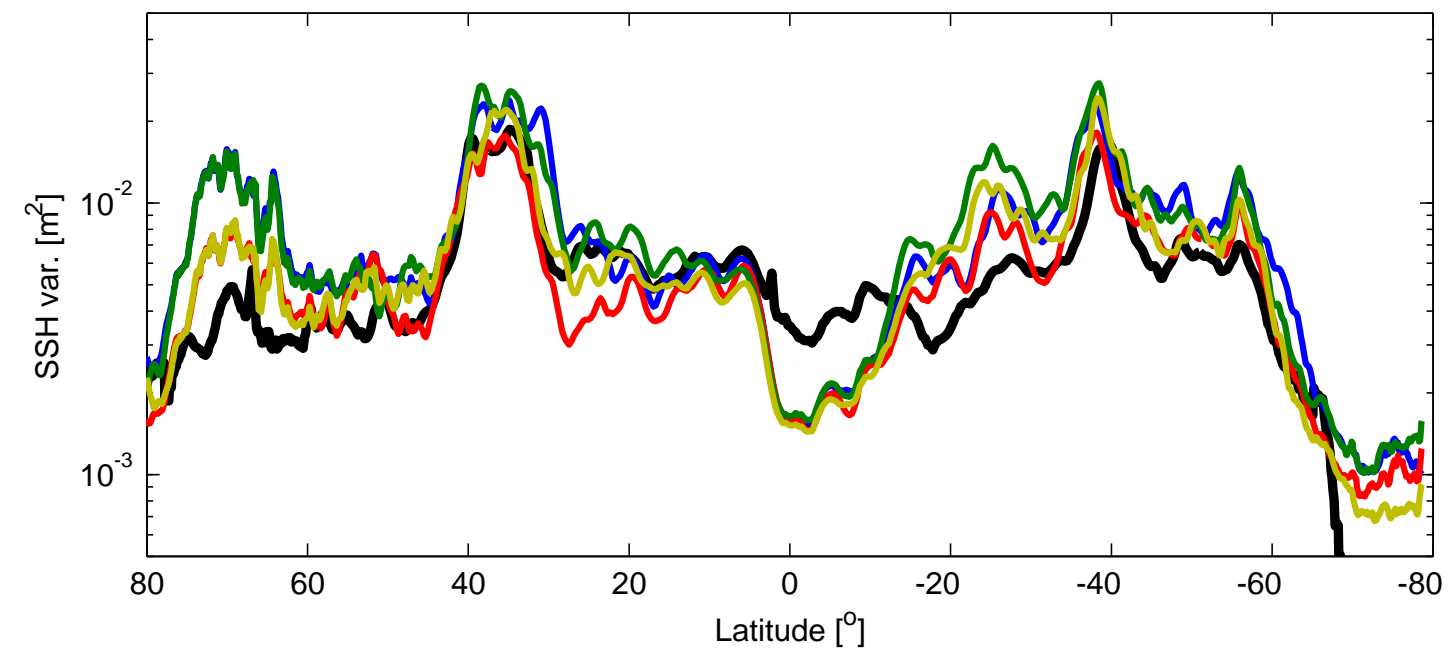

b) Geostrophic surface kinetic energy (SKE) $\left[\mathrm{m}^{2} \mathrm{~s}^{-2}\right]$

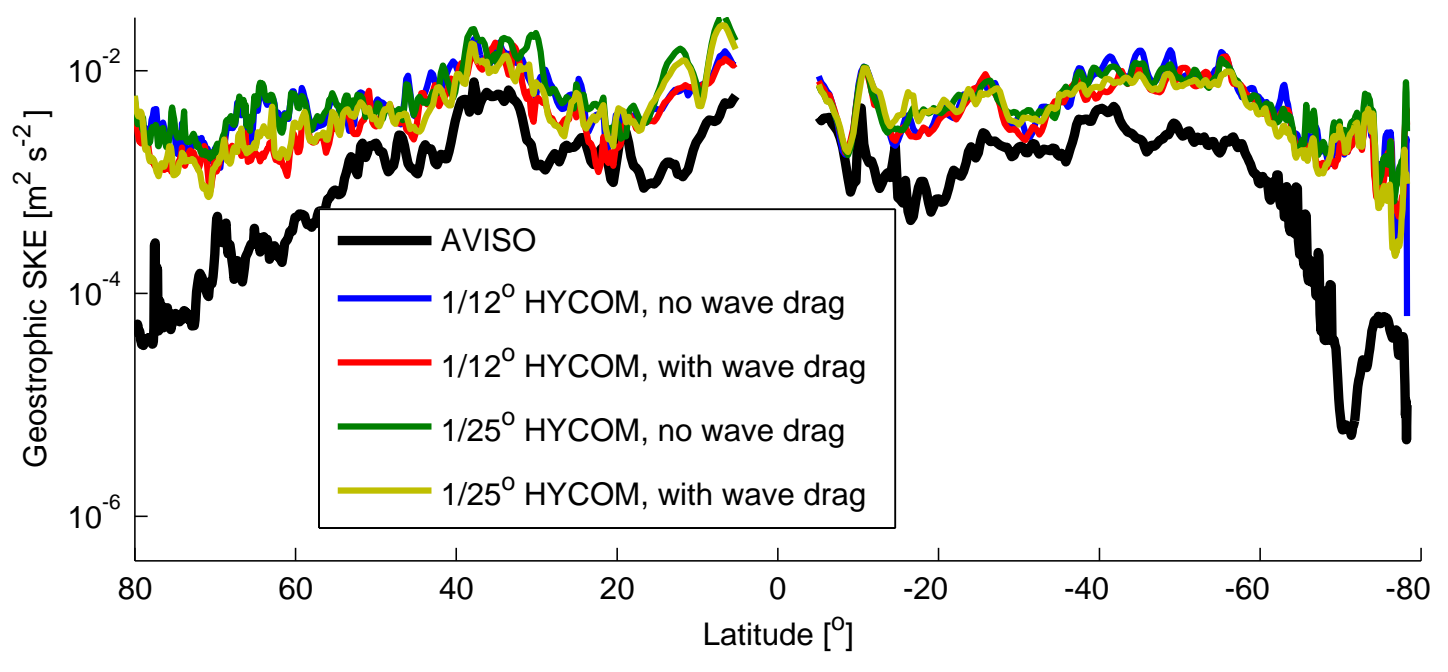

Figure 13: The zonal average of the (a) sea surface height ( $\mathrm{SSH}$ ) variance (units in $\mathrm{m}^{2}$ ) and the (b) geostrophic surface kinetic energy (SKE) (units in $\mathrm{m}^{2} \mathrm{~s}^{-2}$ ) from: $1 / 12^{\circ}$ HYCOM without wave drag (blue), $1 / 12^{\circ}$ HYCOM with wave drag (red), $1 / 25^{\circ}$ HYCOM without wave drag (green), $1 / 25^{\circ}$ HYCOM with wave drag (gold), and the AVISO product (black). Shown are averages over the final year of each model simulation and over 1992-2008 for AVISO. 


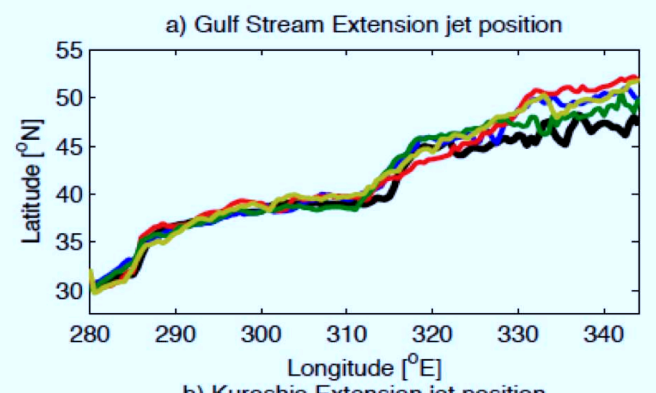

b) Kuroshio Extension jet position

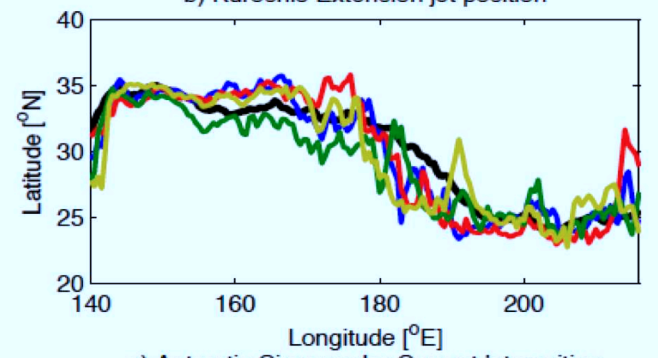

c) Antarctic Circumpolar Current jet position

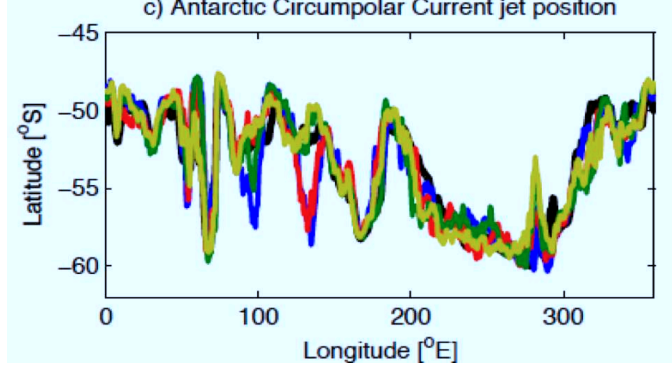

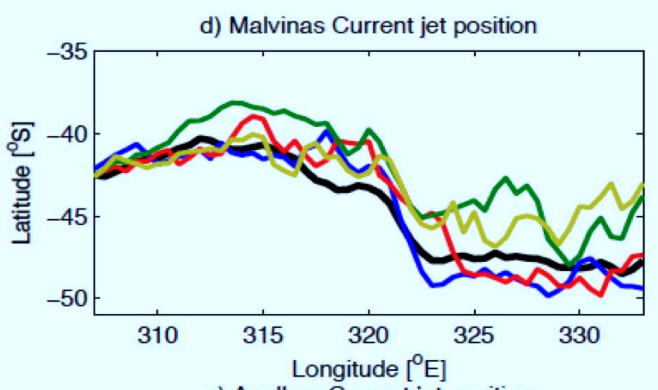

e) Agulhas Current jet position

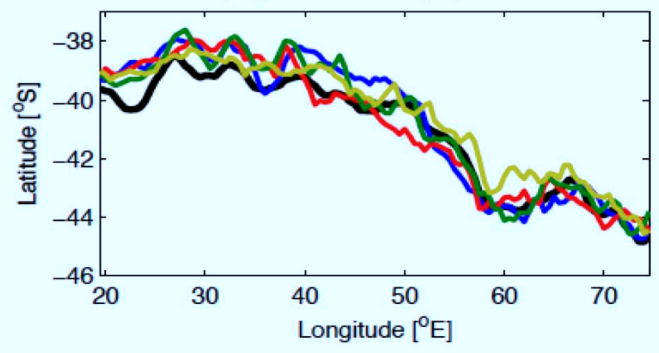

AVISO

1/12th HYCOM, no wave drag

1/12th HYCOM, with wave drag 1/25th HYCOM, no wave drag 1/25th HYCOM, with wave drag

Figure 14: The positions of several intensified jets: (a) Gulf Stream Extension region, (b) Kuroshio

Extension region, (c) Subantarctic Front of the Antarctic Circumpolar Current (ACC) region, (d) Brazil - Malvinas Confluence Current region, and (e) Agulhas Return Current or Retroflection region found from AVISO (thick black), the $1 / 12^{\circ}$ HYCOM simulations without wave drag (blue), $1 / 12^{\circ}$ HYCOM simulation with wave drag (red), $1 / 25^{\circ}$ HYCOM simulation without wave drag (green), and $1 / 25^{\circ}$ HYCOM simulation with wave drag (gold). 

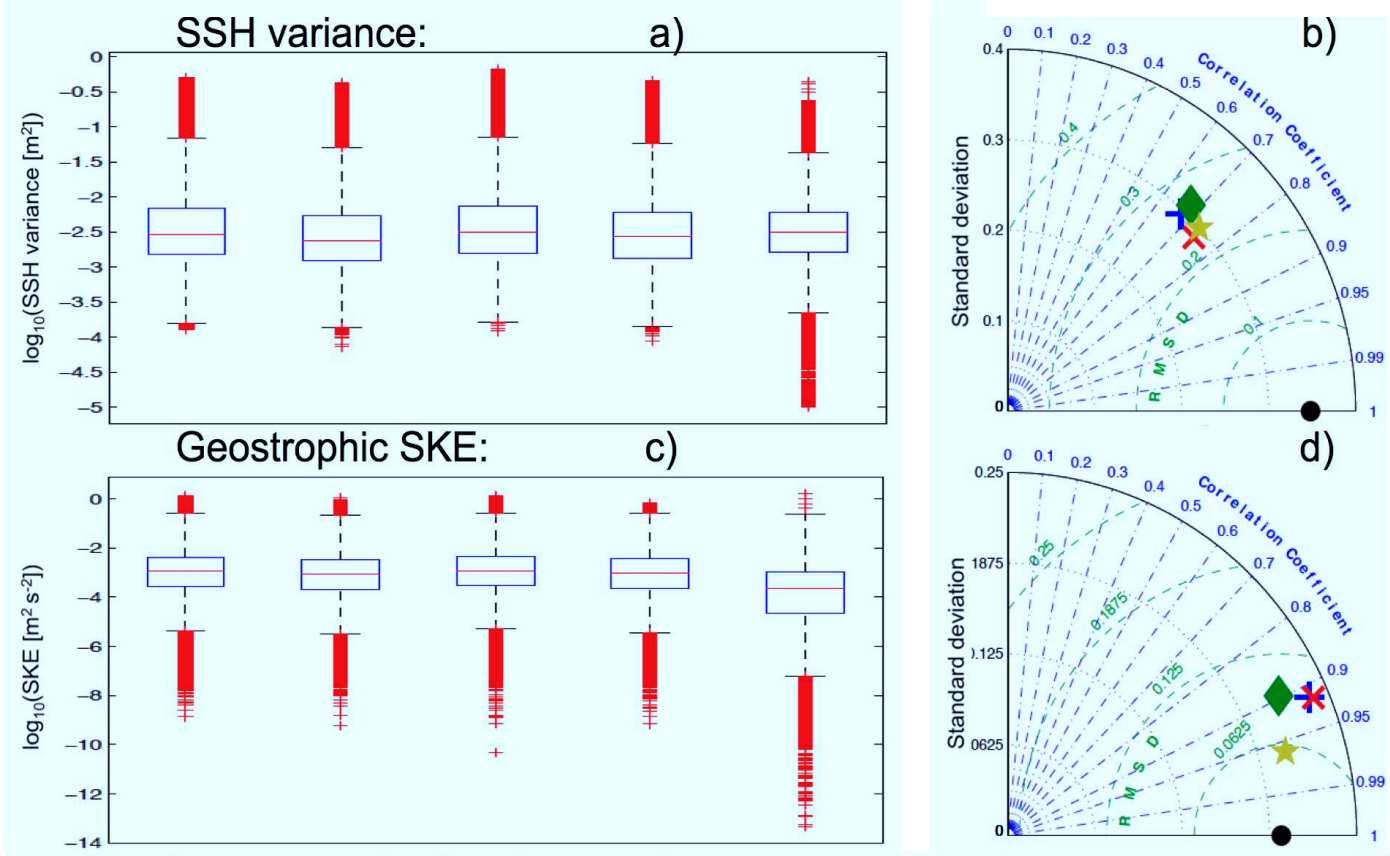

KE at current meter locations: e)
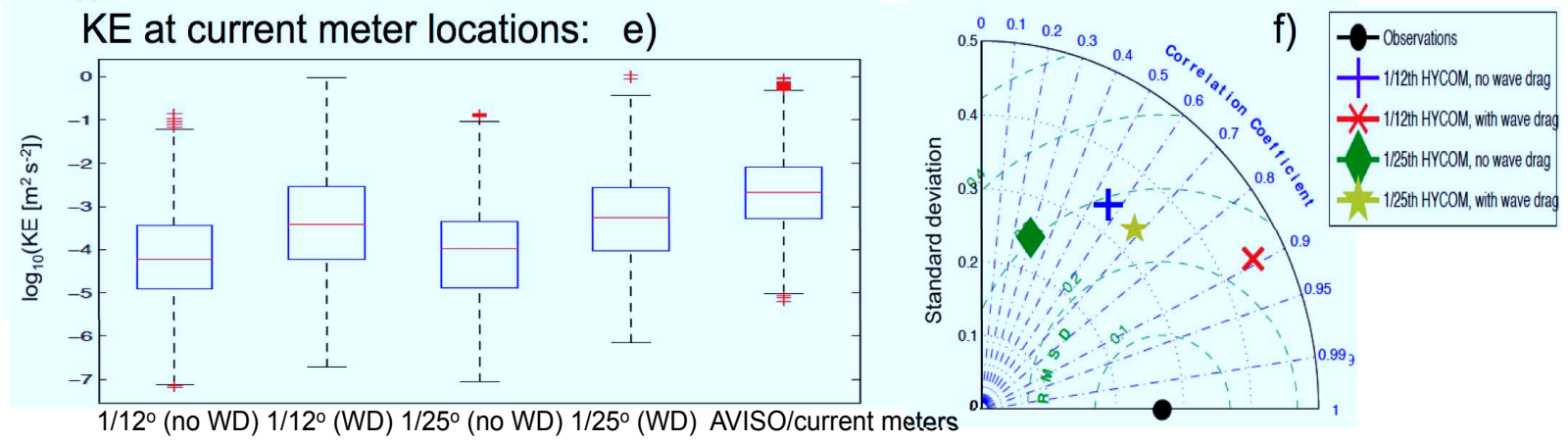

Figure 15: The boxplots (panels a, c, and e) for $1 / 12^{\circ}$ HYCOM without wave drag (no WD, left), $1 / 12^{\circ}$ HYCOM with wave drag (WD, second-to-left), $1 / 25^{\circ}$ HYCOM without wave drag (middle), $1 / 25^{\circ}$ HYCOM with wave drag (second-to-right), and the AVISO- or current meter-informed data (right). The boxplots are computed for the $\log _{10}$ of (a) the sea surface height (SSH) variance, (c) the geostrophic surface kinetic energy (SKE), and (e) the kinetic energy at the current meter locations. The Taylor diagrams (Taylor, 2001; panels b, d, and f) for $1 / 12^{\circ}$ HYCOM without wave drag (blue plusses), $1 / 12^{\circ}$ HYCOM with wave drag (red exes), $1 / 25^{\circ}$ HYCOM without wave drag (green diamonds), and $1 / 25^{\circ}$ HYCOM with wave drag (gold stars) are also shown. The Taylor diagrams compare the $\log _{10}$ of (b) the zonally averaged sea surface height (SSH) variance on the AVISO grid from each simulation with that of AVISO, (d) the zonally averaged geostrophic surface kinetic energy (SKE) using a nine-point stencil (Arbic et al., 2012) on the AVISO grid from each simulation and with a mask applied at grid points within $5^{\circ}$ of the equator with that of AVISO, and (f) the geometric average of the kinetic energies by depth bin from each simulation with that of the low-passed current meter data. The best performing model is closest to the bullseye of the root mean squared deviation (RMSD) from observations (dashed green contours) on the abscissa (correlation of one and relative standard deviation of zero). 


\section{$V_{\text {eff }} N$ in bottom 500 meters $\left(1 / 12^{\circ}\right.$ HYCOM with wave drag)}

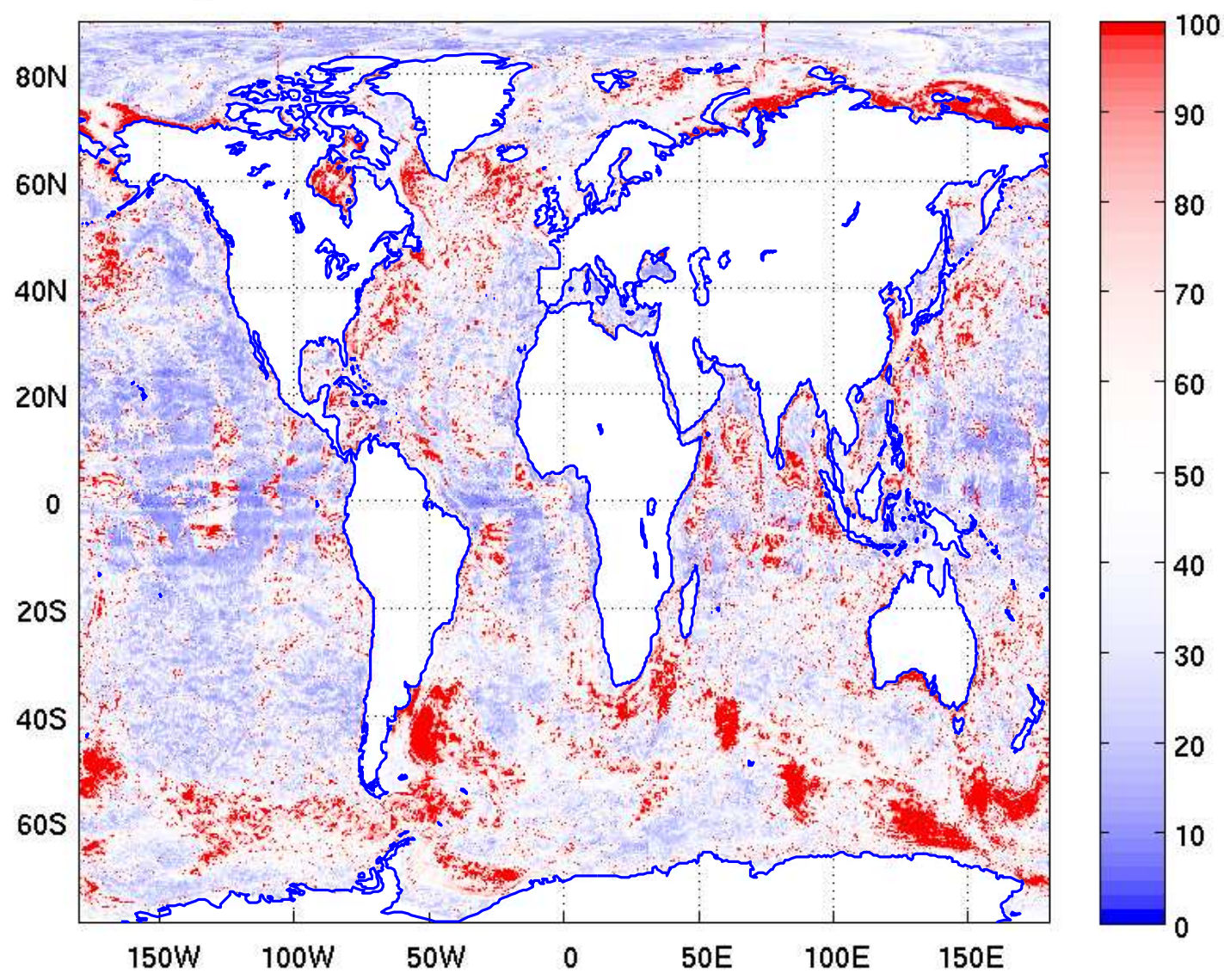

Figure 16: The ratio (given as a percent) of the effective velocity, $V_{\text {eff }}=$ (total dissipation rate)/(horizontal momentum stress), to the velocity averaged over the bottom 500 meters, $V$. Shown is the output from the $1 / 12^{\circ}$ HYCOM simulation with wave drag, averaged over the final year of that model simulation. In blue regions, our assumption that the momentum flux occurs only in the bottom 500 meters results in too much wave drag. In red regions, our deposition of wave drag in the bottom 500 meters is sufficient. 


\section{References}

Andersen, O. B., and P. Knudsen (2009), The DNSC08 mean sea surface and mean dynamic topography, J. Geophys. Res.-Oceans, 114, C11, doi:10.1029/2008JC005179.

Andersen, O. B. (2010), The DTU10 Gravity field and Mean sea surface, Second international symposium of the gravity field of the Earth (IGFS2), Fairbanks, Alaska.

Arbic, B. K., and G. R. Flierl (2004), Baroclinically Unstable Geostrophic Turbulence in the Limits of Strong and Weak Bottom Ekman Friction: Application to Midocean Eddies, J. Phys. Oceanogr., 34, 2257-2273.

Arbic, B. K., and R. B. Scott (2008), On quadratic bottom drag, geostrophic turbulence, and ocenic mesoscale eddies, J. Phys. Oceanogr., 38, 84-103; doi:10.1175/2007JPO3653.1

Arbic, B. K., J. F. Shriver, P. J. Hogan, H. E. Hurlburt, J. L. McClean, E. J. Metzger, R. B. Scott, A. Sen, O. M. Smedstad, A. J. Wallcraft (2009), Estimates of bottom flows and bottom boundary layer dissipation of the oceanic general circulation from global high-resolution models, J. Geophys. Res.-Oceans, 114, C02024, doi:10.1029/2008JC005072.

Arbic, B. K., A. J. Wallcraft, and E. J. Metzger (2010), Concurrent simulation of the eddying general circulation and tides in a global ocean model, Ocean Modelling, 32, 175-187.

Arbic, B. K., R. B. Scott, D. B. Chelton, J. G. Richman, and J. F. Shriver (2012), Effects of stencil width on surface ocean geostrophic velocity and vorticity es- 
timation from gridded satellite altimeter data, J. Geophys. Res.-Oceans, 117, C03029, doi:10.1029/2011JC007367.

Arbic, B. K., M. Müller, J. G. Richman, J. F. Shriver, A. J. Morten, R. B. Scott, G. Serazin, T. Penduff (2014), Geostrophic turbulence in the frequency-wavenumber domain: Eddy-driven low-frequency variability, $J$. Phys. Oceanogr., 44, 2050-2069.

Bell Jr., T. H. (1975), Topographically generated internal waves in the open ocean. J. Geophys. Res., 80(3), 320-327.

Bleck, R. (2002), An oceanic general circulation model framed in hybrid isopycnic-Cartesian coordinates, Ocean Modelling, 37, 55-88.

Boer, G. J., N. A. McFarlane, R. Laprise, J. D. Henderson, and J.-P. Blanchet (1984), The Canadian Climate Centre Spectral Atmospheric General Circulation Model, Atmosphere-Ocean, 22, 397-429.

Bryan, F. O., M. W. Hecht, R. D. Smith (2007), Resolution convergence and sensitivity studies with North Atlantic circulation models. Part I: The western boundary current system, Ocean Modelling, 16, 141-159.

Chassignet, E. P., H. E. Hurlburt, E. J. Metzger, O. M. Smedstad, J. A. Cummings, G. R. Halliwell, R. Bleck, R. Baraille, A. J. Wallcraft, C. Lozano, H. L. Tolman, A. Srinivasan, S. Hankin, P. Cornillon, R. Wesberg, A. Barth, R. He, F. Werner, and J. Wilkin (2009), US GODAE Global Ocean Prediction with the HYbrid Coordinate Ocean Model (HYCOM), Oceanography, 22, (2, Sp. Iss. SI), 6475. 
Chelton, D. B., M. G. Schlax, R. M. Samelson (2011), Global observations of nonlinear mesoscale eddies, Prog. Oceanogr., 91, 167-216.

Decloedt, T., and D. S. Luther (2010), On a simple empirical parameterization of topography-catalyzed diapycnal mixing in the abyssal ocean, J. Phys. Oceanogr., 40, 487-508.

Decloedt, T., and D. S. Luther (2012), Spatially heterogeneous diapycnal mixing in the abyssal ocean: A comparison of two parameterizations to observations, J. Geophys. Res.-Oceans, 117, C11025, doi:10.1029/2012JC008304.

Dengg, J. (1993), The problem of Gulf Stream separation: A barotropic approach, J. Phys. Oceanogr., 23, 2182-2200.

Ducet, N., P.-Y. Le Traon, and G. Reverdin (2000), Global high-resolution mapping of ocean circulation from TOPEX/Poseidon and ERS-1 and -2, J. Geophys. Res., 105, 19,477-19,498.

Eckermann, S. D. (2011), Explicitly stochastic parameterization of nonorographic gravity wave drag, J. Atmos. Sci., 68, 1749-1765.

Egbert, G. D., R. D. Ray, and B. G. Bills (2004), Numerical modeling of the global semidiurnal tide in the present day and in the Last Glacial Maximum, $J$. Geophys. Res., 109, C03003; doi:10.1029/2003JC001973

Garner, S. T. (2005), A Topographic Drag Closure Built on an Analytical Base Flux, J. Atmos. Sci., 62, 2302-2315.

Goff, J. A., and T. H. Jordan (1988), Stochastic Modeling of Seafloor Morphol- 
ogy Inversion of Sea Beam Data for Second-Order Statistics, J. Geophys. Res., 93(B11), 13,589-13,608.

Goff, J. A. (2010), Global prediction of abyssal hill root-mean-square heights from small-scale altimetric gravity variability, J. Geophys. Res., 115, B12104; doi:10.1029/2010JB007867.

Goff, J. A., and B. K. Arbic (2010), Global prediction of abyssal hill roughness statistics for use in ocean models from digital maps of paleo-spreading rate, paleo-ridge orientation, and sediment thickness, Ocean Modelling, 32, 36-43.

Griffies, S. M., C. Böning, F. O. Bryan, E. P. Chassignet, R. Gerdes, H. Hasumi, A. Hirst, A.-M. Treguier, and D. Webb (2000), Developments in ocean climate modelling, Ocean Modelling, 2, 123-192.

Hallberg, R., and A. Gnanadesikan, 2006: The Role of Eddies in Determining the Structure and Response of the Wind-Driven Southern Hemisphere Overturning: Results from the Modeling Eddies in the Southern Ocean (MESO) Project, $J$. Phys. Oceanogr., 36, 2232-2252.

Halliwell, G. R. (2004), Evaluation of vertical coordinate and vertical mixing algorithms in the HYbrid-Coordinate Ocean Model (HYCOM), Ocean Modelling, 7, 285-322.

Hurlburt, H. E., and P. J. Hogan (2008), The Gulf Stream pathway and the impacts of the eddy-driven abyssal circulation and the Deep Western Boundary Current, Dyn. Atmos. Ocean., 45, 71-101.

Hurlburt, H. E., E. J. Metzger, P. J. Hogan, C. E. Tilburg, and J. F. Shriver (2008), 
Steering of upper ocean currents and fronts by the topographically constrained abyssal circulation, Dyn. Atmos. Ocean., 45, 102-134.

Jayne, S. R., and L. C. St. Laurent (2001), Parameterizing Tidal Dissipation over Rough Topography, Geophys. Res. Lett., 28(5), 811-814.

Kallberg, P., A. Simmons, S. Uppala, and M. Fuentes (2004), The ERA-40 Archive, ERA-40 Project Report Series No. 17, ECMWF.

Kelly, K. A., L. Thompson, W. Cheng, and E. J. Metzger (2007), Evaluation of HYCOM in the Kuroshio Extension region using new metrics, J. Geophys. Res., 112, C01004.

Large, W. G., J. C. McWilliams, and S. C. Doney (1994), Oceanic vertical mixing: a review and a model with a nonlocal boundary layer parameterization, Rev. Geophys. 32, 363-403.

Le Traon, P.-Y., F. Nadal, and N. Ducet (1998), An improved mapping method of multisatellite altimeter data, J. Atmos. Ocean. Tech., 15, 522-534.

Lott, F., and M. J. Miller (1997), A new subgrid-scale orographic drag parametrization: its formulation and testing, Q. J. R. Meteorol. Soc., 123, 101127.

Maltrud, M. E., J. L. McClean (2005), An eddy resolving global 1/10 ocean simulation, Ocean Modelling, 8, 31-54.

Marotzke, J. (1991), Influence of convective adjustment on the stability of the thermohaline circulation, J. Phys. Oceanogr., 21, 903-907. 
Marshall, D. P., and A. C. Naveira-Garabato (2008), A conjecture on the role of bottom-enhanced diapycnal mixing in the parameterization of geostrophic eddies, J. Phys. Ocean., 38, 1607-1613.

Melet, A., R. Hallberg, S. Legg, and K. Polzin (2013), Sensitivity of the Ocean State to the Vertical Distribution of Internal-Tide-Driven Mixing, J. Phys. Oceanogr., 43, 602-615.

Melet, A., R. Hallberg, S. Legg, and M. Nikurashin (2014), Sensitivity of the Ocean State to Lee Wave-Driven Mixing, J. Phys. Ocean., 44, 900-921.

Melet, A., R. Hallberg, A. Adcroft, M. Nikurashin, and S. Legg (2015), Energy flux into internal lee waves: sensitivity to future climate changes using linear theory and a climate model, J. Clim., 28, 2365-2384.

Munk, W., and C. Wunsch (1998), Abyssal recipes II: Energetics of tidal and wind mixing, Deep Sea Res., Part I, 45, 1977-2010.

Naveira-Garabato, A. C., K. L. Polzin, B. A. King, K. J. Heywood, and M. Visbeck (2004), Widespread intense turbulent mixing in the Southern Ocean, Science, 303, 210-213.

Nikurashin, M., and R. Ferrari (2010a), Radiation and dissipation of internal waves generated by geostrophic motions impinging on small-scale topography: Theory, J. Phys. Ocean., 40, 1055-1074.

Nikurashin, M., and R. Ferrari (2010b), Radiation and dissipation of internal waves generated by geostrophic motions impinging on small-scale topography: Application to the Southern Ocean, J. Phys. Ocean., 40, 2025-2042. 
Palmer, W. R., G. J. Shutts, and R. Swinbank (1986), Alleviation of a systematic westerly bias in general circulation and numerical weather prediction models through an orographic gravity wave drag parameterization, Q. J. R. Meteorol. Soc., 112(474), 1001-1039.

Pierrehumbert, R. T. (1987), An Essay on the Parameterization of Orographic Gravity Wave Drag, "Observation, Theory, and Modelling of Orographic Effects", European Center for Medium Range Weather Forecasts, Reading, U. K., 251-282.

Polzin, K. L. (2008), Mesoscale eddy-internal wave coupling. Part I: Symmetry, wave capture, and results from the mid-ocean dynamics experiment, J. Phys. Oceanogr., 38, 2556-2574.

Polzin, K. L. (2010), Mesoscale eddy-internal wave coupling. Part II: Energetics and results from POLYMODE, J. Phys. Oceanogr., 40, 789-801.

Rintoul, S. R., S. Sokolov, M. J. M. Williams, B. Pea Molino, M. Rosenberg, and N. L. Bindoff (2014), Antarctic Circumpolar Current transport and barotropic transition at Macquerie Ridge, Geophys. Res. Lett., 41, 7254-7261, doi:10.1002/2014GL061880.

Riviere, P., A. M. Treguier, P. Klein (2004), Effects of bottom friction on nonlinear equilibration of an oceanic baroclinic jet, J. Phys. Oceanogr., 34, 416-432.

Rosmond, T. E., J. Teixeira, M. Peng, T. F. Hogan, and R. Pauley (2002), Navy Operational Global Atmospheric Prediction System (NOGAPS): Forcing for Ocean Models, Oceanography, 15, 99-108. 
Scott, R. B., and Y. Xu (2009), An update on the wind power input to the surface geostrophic flow of the World Ocean, Deep-Sea Res. I, 56, 295-304.

Scott, R. B., B. K. Arbic, E. P. Chassignet, A. C. Coward, M. Maltrud, W. J. Merryfield, A. Srinivasan, A. Varghese (2010), Total kinetic energy in four global eddying ocean circulation models and over 5000 current meter records, Ocean Modelling, 32, 157-169.

Sen, A., R. B. Scott, and B. K. Arbic (2008), Global energy dissipation rate of deep-ocean low-frequency flows by quadratic bottom boundary layer drag: Computations from current-meter data, Geophys. Res. Lett., 35, L09606, doi:10.1029/2008GL033407.

Shaw, T. A., T. G. Shepherd (2007), Angular momentum conservation and gravity wave drag parameterization: Implications for climate models, J. Atmos. Sci, 64, 190-203.

Shepherd, T. G., T. A. Shaw (2004), The angular momentum constraint on climate sensitivity and downward influence in the middle atmosphere, J. Atmos. Sci, 61, 2899-2908.

Shorack, G. R., and J. A. Wellner (1986), Empirical Processes with Applications to Statistics, Wiley. p. 239. ISBN 047186725X.

Smagorinsky, J. (1993), Large eddy simulation of complex engineering and geophysical flows, in Evolution of Physical Oceanography, edited by B. Galperin, and S. A. Orszag, pp. 3-36. Cambridge University Press.

Srinivasan, A., Z. Garraffo, and M. Iskandarani (2009), Abyssal circulation in 
the Indian Ocean from a $1 / 12^{\circ}$ resolution global hindcast, Deep-Sea Res. I, 56, 1907-1926.

St. Laurent, L. C., J. M. Toole, and R. W. Schmitt (2001), Buoyancy forcing by turbulence above rough topography in the abyssal Brazil Basin, J. Phys. Oceanogr., 31, 3476-3495.

St. Laurent, L. C., H. L. Simmons, and S. R. Jayne (2002), Estimating tidally driven mixing in the deep ocean, Geophys. Res. Lett., 29(23), 2106; doi:10.1029/2002GL015633.

St. Laurent, L., A. Naveira Garabato, J. Ledwell, A. Thurnherr, J. Toole, and A. Watson (2012), Turbulence and diapycnal mixing in Drake Passage, J. Phys. Oceanogr., 42, 2143-2152.

Stewart, K. D., J. A. Saenz, A. McC. Hogg, G. O. Hughes, and R. W. Griffiths (2014), Effect of topographic barriers on the rates of available potential energy conversion of the oceans, Ocean Modelling, 76, 31-42.

Taylor, G. I. (1919), Tidal friction in the Irish Sea, Philos. Trans. R. Soc. London, Ser. A, 220, 1-33.

Taylor, K. E. (2001), Summarizing multiple aspects of model performance in a single diagram, J. Geophys. Res.-Atmospheres, 106(D7), 7183-7192, doi:10.1029/2000JD900719.

Thompson, A. F., W. R. Young (2006), Scaling baroclinic eddy fluxes: Vortices and energy balance, J. Phys. Oceanogr., 36, 720-738. 
Thoppil, P. G., J. G. Richman, and P. J. Hogan (2011), Energetics of a global ocean circulation model compared to observations, Geophys. Res. Lett., 38, L15607, doi:10.1029/2011GL048347.

Timko, P. G., B. K. Arbic, J. G. Richman, R. B. Scott, E. J. Metzger, and A. J. Wallcraft (2013), Skill testing a three-dimensional global tide model to historical current meter records, J. Geophys. Res.-Oceans, 118, 6914-6933, doi:10.1002/2013JC009071.

Trossman, D. S., B. K. Arbic, S. T. Garner, J. A. Goff, S. R. Jayne, E. J. Metzger, and A. J. Wallcraft (2013), Impact of parameterized lee wave drag on the energy budget of an eddying global ocean model, Ocean Modelling, 72, 119-142.

Wallcraft, A. J., A. B. Kara, and H. E. Hurlburt (2005), Convergence of Laplacian diffusion versus resolution of an ocean model, Geophys. Res. Lett., 32, L07604; doi:10.1029/2005GL022514.

Webb, D. J., and N. Suginohara (2001), Vertical mixing in the ocean, Nature, 409, 37.

Willebrand, W., Barnier, B., Boning, C., Dieterich, C., Killworth, P. D., Le Provost, C., Jia, Y., Molines, J.-M., New, A. L. (2001), Circulation characteristics in three eddy-permitting models of the North Atlantic, Progr. Oceanogr., 48, $123-161$.

Wright, C. J., R. B. Scott, D. Furnival, P. Ailliot, and F. Vermet (2013), Global Observations of Ocean-Bottom Subinertial Current Dissipation, J. Phys. Oceanogr., 43, 402-417. 
1117 Wright, C. J., R. B. Scott, P. Ailliot, and D. Furnival (2014), Lee wave generation rates in the deep ocean, Geophys. Res. Lett., 41; doi:10.1002/2013GL059087. 